\title{
The Role of Islamic Legitimacy Basis to Combat the Financial Corruption in Kuwait
}

\author{
Melfi Muhammed Al Azemi \\ Ministers Council, \\ Kuwait. \\ Email: wstead@live.com
}

\author{
Abdel Majeed Al Omari \\ International Islamic University Malaysia, \\ Malaysia. \\ Email: alamri@iium.edu.my \\ Tawfeeq Al Omrani \\ International Islamic University Malaysia, \\ Malaysia.
}

Received March, 2020; Accepted May, 2020

\begin{abstract}
The study aims to identify the role of Islamic Sharia to alleviate the problem of financial corruption in Kuwait. The researchers rely on the descriptive method. An extensive literature review was performed with regards to the legitimate ways to combat the financial corruption. The study has conducted interviews with Kuwaiti religious officials who have a long experience in the field of financial corruption. Results indicate that the role of Islamic Sharia is almost absent due to the lack of religious officials' intervention. Their role in the field of combating financial corruption should be activated and not only restricted to media. This fact had increased the level of the financial corruption according to the annual financial corruption index. The study conveys important remarks. Kuwaiti official ministries and related organizations should embrace Islamic Sharia and rely on the wisdom of religious officials. To combat financial corruption, governments should reinforce the application of Sharia law in Kuwait since it was completely ignored in the past.
\end{abstract}

Keywords: Financial Corruption; Legitimacy Basis.

Type: Research paper

هدفت الدراسة إلى التعرف على دور التأصيل الشرعي في محاربة تسونامي الفساد المالي في دولة الكويت. اعتمد الباحث على المنهج

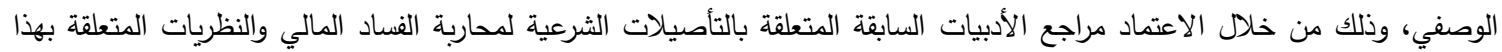
الجانب، إلى جانب إجراء عدد من المقابلات مع رجال الدين في دولة الكويت للوقوف على أسباب استشراء هذه الظاهرة ودور الشريعة الإسلامية في ذلك خاصة ممن لهم دراية كبيرة في قضايا الفساد المالي بدولة الكويت. وقد بينت النتائج بأن دور الثريعة في مكافحة الفساد المالي هو مقتصر فقط على وسائل الإعلام وليس الوزارات والجهات المسؤولة في البلاد، وهذا يعود إلى تجاهل الحكومات المتعاقبة لدور الثريعة الاسلامية في مجال مكافحة الفساد المالي المتصاعد في دولة الكويت حسب مؤشر الفساد المالي السنوي ، إلا أن الثريهة الإسلامية ترزخ بكل ما ما هو ناجع في محاربة آفة الفساد المالي وقطع دابره.الكلمات المفتاحية: الجودة، إدارة الجودة الثاملة، مؤسسات

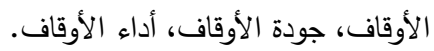
الكلمات الالة: الفساد المالي، التأصيل الشرعي. 
الفساد بمفهومه العام هو إحدى الظواهر السلبية التى تعانى منها جميع دول العالم، خصوصاً الدول النامية التي تؤثر فيها بشكل كبير على مقوماتها الأساسية، وذلك بسبب فقدان التوازن فى توزيع الحقوق؛ مما يؤدى بطبيعة

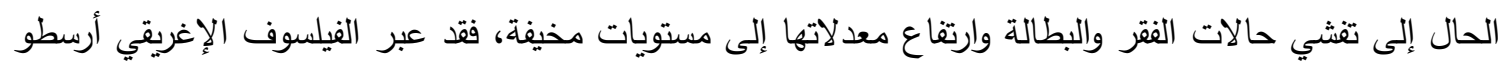
عن عمق هذه الظاهرة وخطورتها بقوله: "إن الفساد ليس الموت نفسه ولكناء على الأقل؛ حركة نحو الموت". وإذا إلى

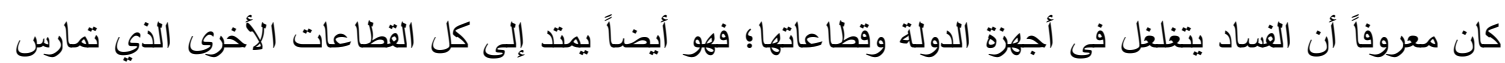

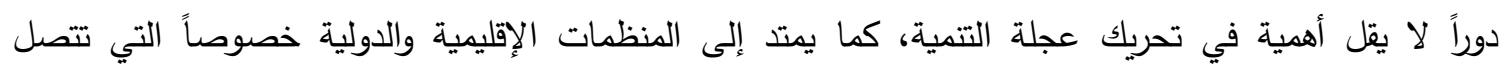

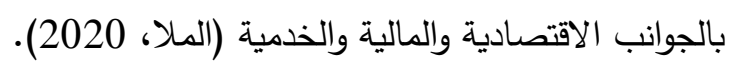
ومما لا شك فيه بأن الثريعة الإسلامية مبنية على جلب المصالح وتكثيرها ودرو المفاسد وتقليلها، ومن المصالح المعتبرة التي جاءت بها النصوص الكريمة صيانة المال الذي يعد حفظه من الضروريات في الإسلام، ولهذا حث الثارع الحكيم على الأمانة وأثنى على أهلها، وحرم الاعتداء على أموال الناس وإفسادها، تماما كما حرم الاعتداء

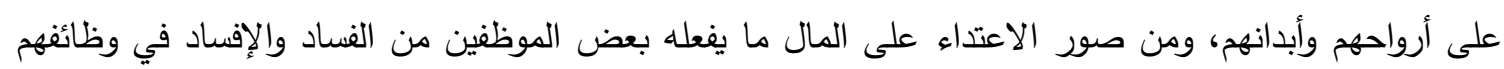

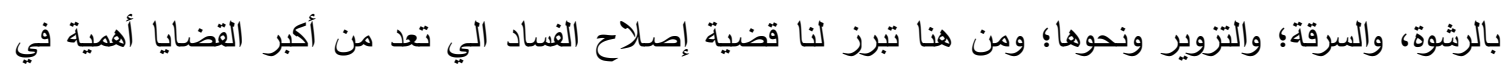

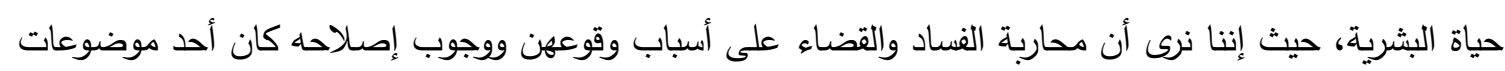

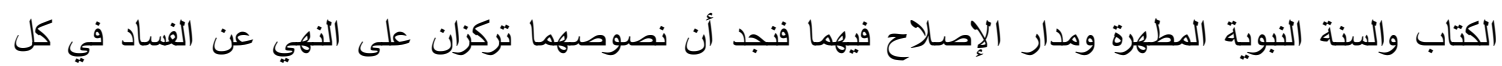

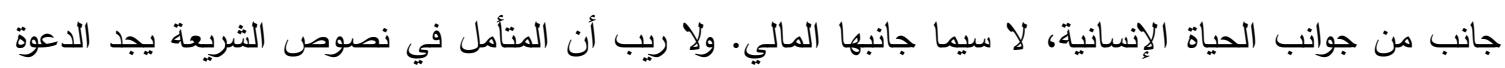

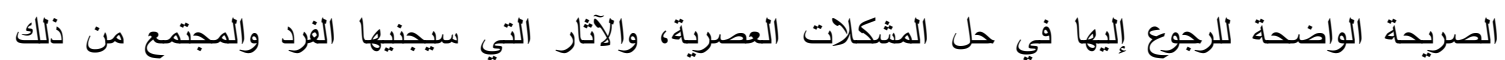

$$
\text { (المحروق، 2016). }
$$

ومن هنا جاء الدراسة الحالية حول وجوب العودة للشريعة الإسلامية أي التركيز على التأصيل الثرعي، حتى وإن اقتصر الأمر فقط على محاربة الفساد وأسبابه، والاستفادة بهدي الثريعة الاسلامية السمحاء في إصلاح أحوال الناس وأخلاقهم وتصرفاتهم وجميع علاقاتهم أفراداً وجماعات. مشكلة الدراسة وأسئلتها إن الحديث عن الفساد حديث قديم جديد تتاوله الإسلام في مصادر تشريعه المختلفة وكثر الحديث حوله مؤخرا ، إلا أن الفشل في المعالجة كان واضحا حيث أن أهم أسباب الفشل عدم وضوح المنهج وإغفال الجانب التأصيلي القانوني والثرعي للفساد المالي وأسبابه. وبناء على ما سبق فإن مشكلة البحث تتمثل في السؤال الرئيسي التالي: ما دور

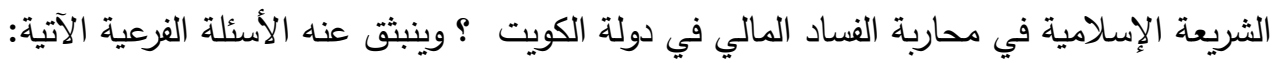

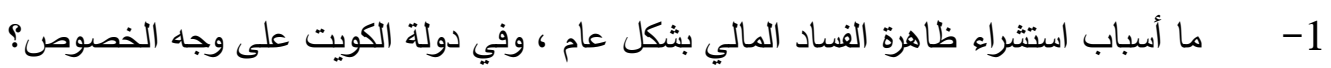
2 - ما أثر التأصيل الثرعي في محاربة ظاهرة الفساد المالي بدولة الكويت ؟

أهداف الدراسة هدفت الدراسة الحالية إلى الآتي: 1- - التعرف على أسباب استشراء ظاهرة الفساد المالي بشكل عام ، وفي دولة الكويت على وجه الخصوص. 2- التعرف على أثر التأصيل الثرعي في محاربة ظاهرة الفساد المالي بدولة الكويت. 
أهمية الدراسة

يمكن تلخيص أهمية هذه الدراسة بما يأتي: 1.نتائج هذه الدراسة تفيد المسؤولين في مكافحة الفساد بدولة الكوبيت.

2. نتائج الدراسة تفيد المسؤولين في التعرف على أسباب الفساد المالي في دولة الكويت والأخذ بتوصيتها. 4.هذه الدراسة تعد من الدراسات الأولى في دولة الكويت -على حد علم الباحث- والتي تتتاول أثر التأصيل

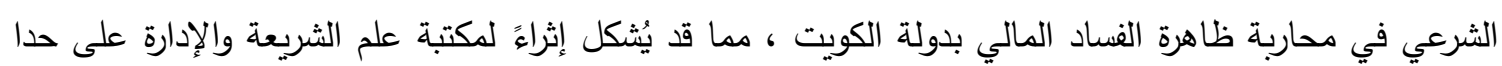
سواء.

حدود الاراسة:

تتحدد حدود هذه الدراسة بما يأتي:

-الحدود الموضوعية: تتتاول الدراسة أثر التأصيل الشرعي في محاربة ظاهرة الفناد المالي بدولة الكويت

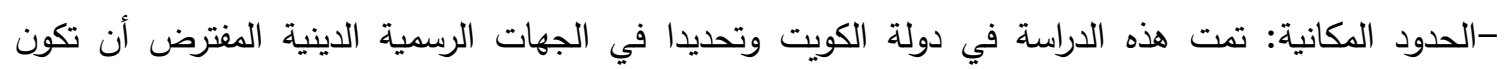

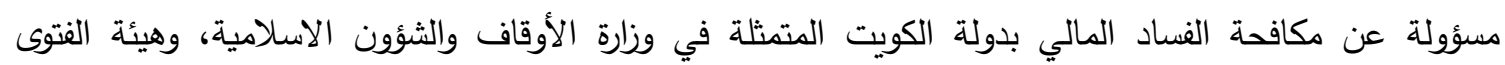
والتشريع. -الحدود الزمنية: أجريت هذه الدراسة خلال شهر نوفمبر لسنة 2020. -الحدود البشرية: المسؤولين في وزارة الأوقاف والثؤون الاسلامية، وهيئة الفتوى والتشريع. بدولة الكويت وعددهم (10) أفراد.

مصطلحات الدراسة: قام الباحث بتعريف المصطلحات الواردة في الدراسة وفقاً للتعريفات الواردة في المراجع العربية والأجنبية، وسيتم تعريف بعض المصطلحات وفقا لخبرات الباحث الذاتية، وفيما يلي تعريف لبعض مصطلحات الدراسة:

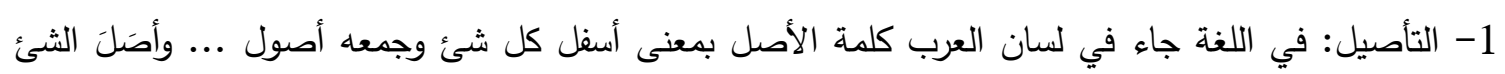

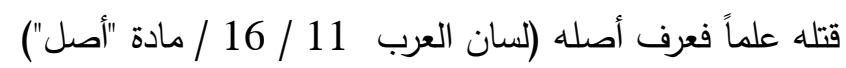
أما اصطلاحا فيعرف التأصيل بأنه رد القضايا إلى أصولها بعد التعمق في بحثها وفهمها، وهذا المعنى قريب من المعنى اللغوي السابق (محمدن، 2010). وإجرائيا يعرف التأصيل بأنه إرجاع الثئ إلى أصله بحثاً عن معرفة كنهه وحقيقته. 2- التأصيل الثرعي: ويقصد به اصطلاحا بأنه إرجاع القول والفعل إلى أصل الثئ وأساس يقوم عليه وأن القرآن آنسان

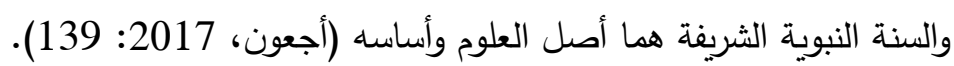

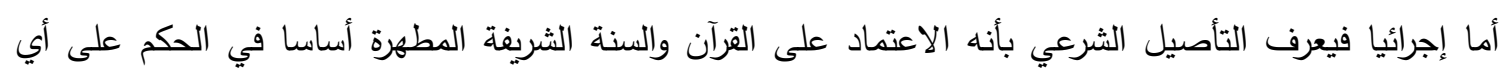
تعامل كان. 3- الفساد: الفساد في اللغة عكس الإصلاح وهو بمعنى التلف، والاضطراب والخلل، والقحط، وإلحاق الضرر ، وأخذ المال ظلما (ابن أبو الكرم، 2017) ، ومنه قوله تعالى (ويسعون في الأرض فسادا) (القرطبي، 2015)

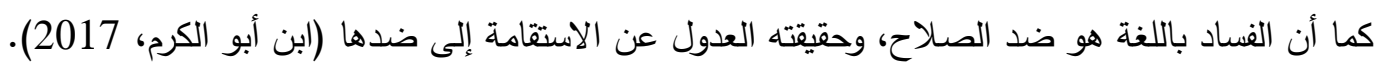
ويعرف الفساد اصطلاحا بأنه اساءة استعمال مركز ما لتحقيق مكسب خاص (محارب، 2016). 
أما إجرائيا فيعرف الفساد بأنه تقديم المصلحة الثخصية على المصلحة العامة بما يضر بمكان العمل ومصالح الناس الآخرين الذين لا ذنب لهم.

4- الفساد المالي: يعرف الفساد المالي اصطلاحا بأنه ذلك السلوك المنافي للقوانين والاخلاق والقائم على الإخلال بالمصالح والواجبات العامة من خلال استغلال المال العام لتحقيق مصالح خاصة، وهو ليس حكرا على النشاط

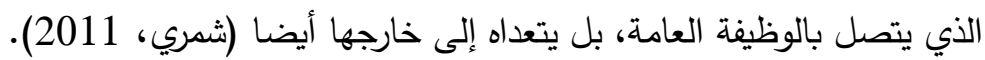
وإجرائيا يمكن تعريف الفساد المالي بأنه العبث بالمال العام لتحقيق مآرب شخصية أو لمصلجة جهة ما، في غياب

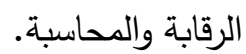

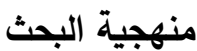

اعتمد الباحث على المنهج الوصفي، وذلك من خلال الاعتماد مراجع الأدبيات السابقة المتعلقة بالتأصيلات الثرعية

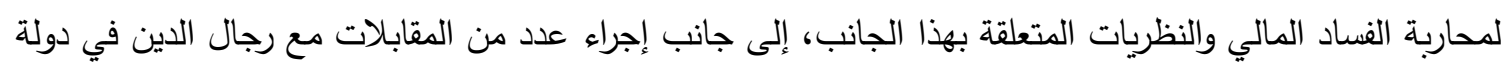
الكويت للوقوف على أسباب استشراء هذه الظاهرة ودور الشربعة الإسلامية في ذلك.

الإطار النظري والدراسات السابقة 1-مفهوم الفساد: الفساد في اللغة عكس الإصلاح وهو بمعنى التلف، والاضطراب والخلل، والقحط، وإلحاق الضرر، وأخذ المال ظلما (ابن أبو الكرم، 2017: 202) ، ومنه قوله تعالى (ويسعون في الأرض فسادا) (القرطبي، 2005: 111).

كما أن الفساد باللغة هو ضد الصلاح، وحقيقته العدول عن الاستقامة إلى ضدها (ابن أبو الكرم، 2017: 55) .

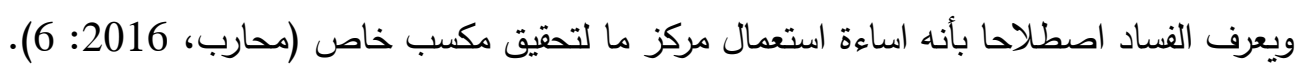
أما إجرائيا فيعرف الفناد بأنه تقديم المصلحة الثخصية على المصلحة العامة بما يضر بمكان العمل ومصالح الناس الآخرين الذين لا ذنب لهم. 2- الفساد المالي: يعرف الفساد المالي اصطلاحا بأنه ذلك السلوك المنافي للقوانين والاخلاق والقائم على الإخلاد

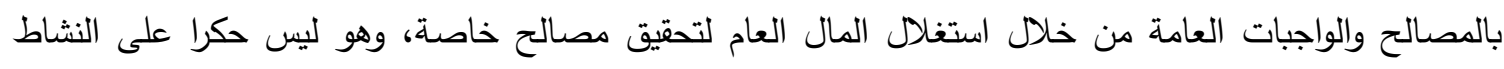

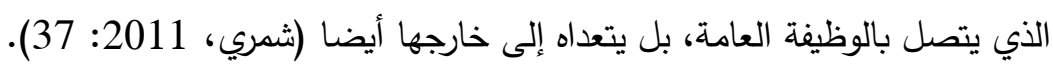

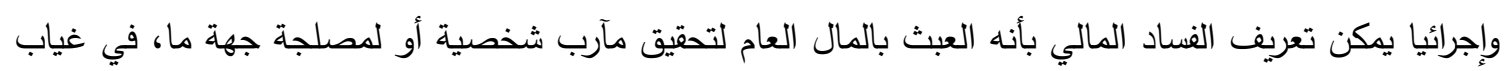
الرقابة والمحاسبة.

3- التأصيلات الشرعية للفساد المالي

إن الحديث عن الفساد حديث قديم جديد تتاوله الإسلام في مصادر تشريعه المختلفة وكثر الحديث حوله مؤخرا. - ذكر الفساد في القرآن والسنة لقد كان موقف القرآن والسنة من الفساد واضحاً وفاصلاً إذ أنهما حرما كل أنواعه وأشكاله، وذلك بذمه وبيان آثاره

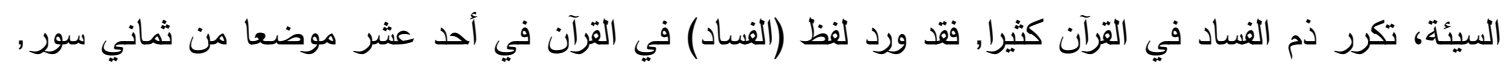

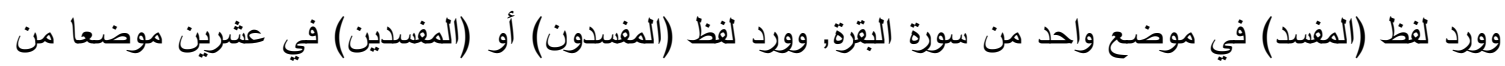
اثنتي عشرة سورة, وورد لفظ (يفسدون) في خمسة مواضع من خمس سور (عبد الباقي، 1945:

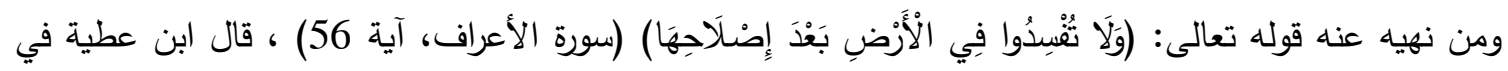

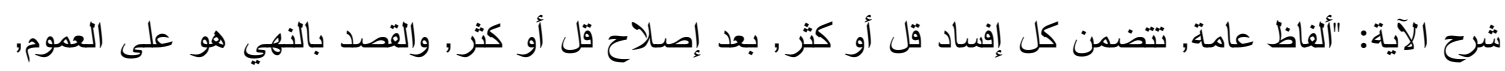


وتخصيص شيء دون شيء في هذا تحكّم إلا أن يقال على وجهة المثال" (بن غالب، 2002) ، وقال سبحانه:

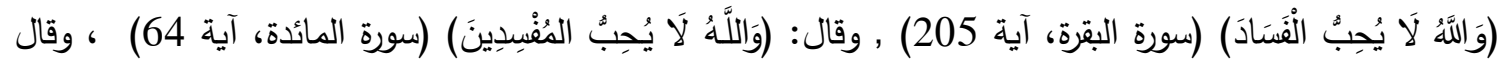

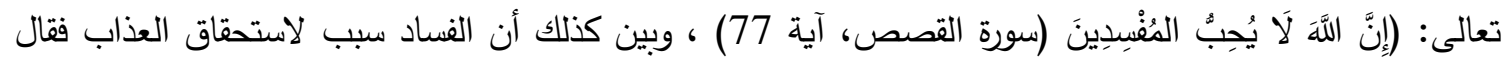

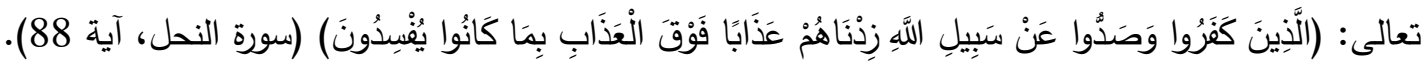

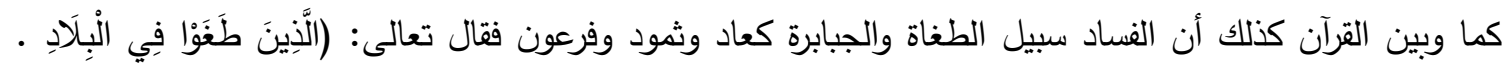

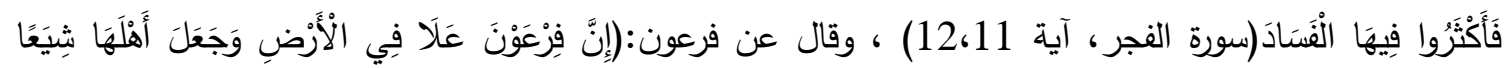

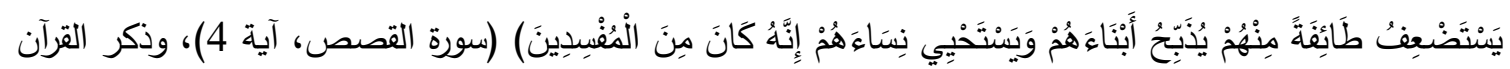

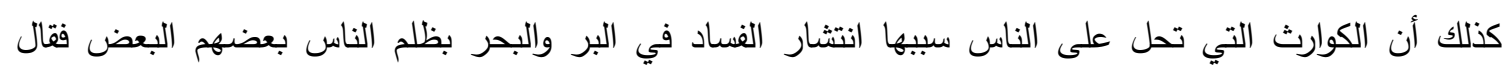

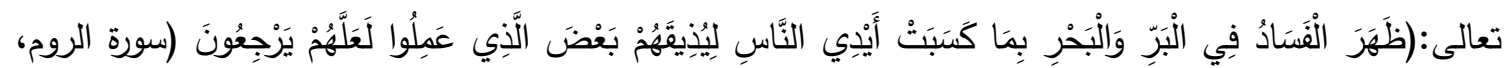

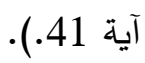

ونهى نبيه صلى الله عليه وسلم عن طلب الفساد أو تتبع سبله وطرقه، وهو نهي لعموم الأمة كذلك فقال تعالى : (وَلَّا

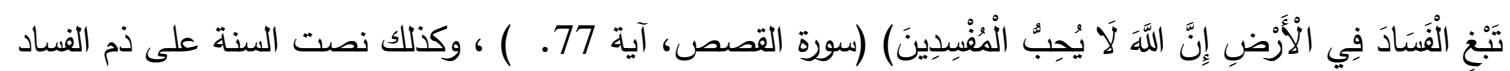

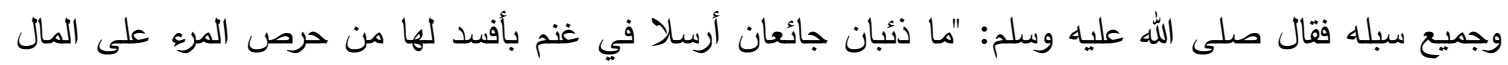

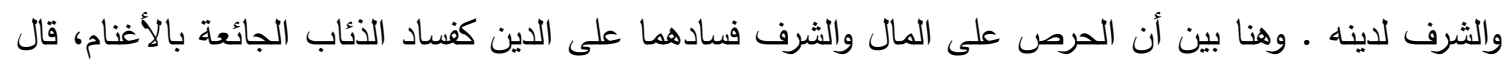
ابن رجب الحنبلي: "فهذا مثل عظيم جدا, ضربه النبي صلى الله عليه وسلم لفساد دين المسلم بالحرص على المال

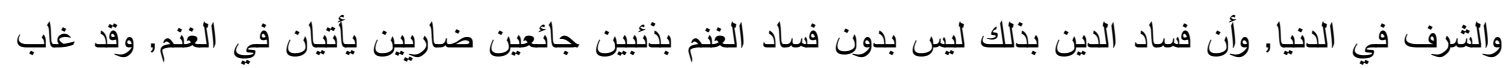

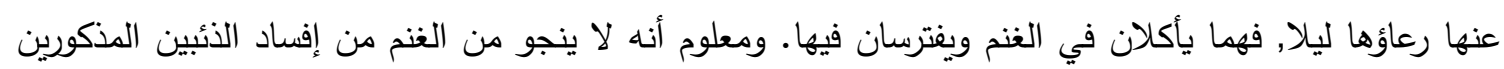

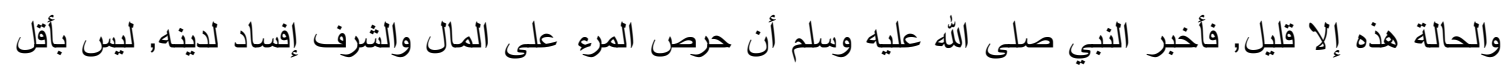

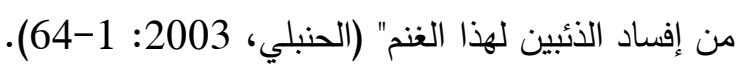
وكذلك صور النبي صلى الله عليه وسلم الأعمال بالوعاء إذا حسن قعرها حسنت وإن فسد أسفلها فسدت فقال: " إنما

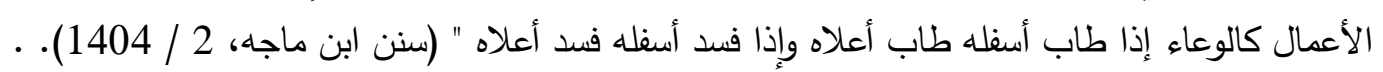
ومن هنا جاءت القواعد الثرعية مقررة هذا التحريم ومنها: "ما كان مظنة لفساد خفي غير منضبط علق الحكم به إداه

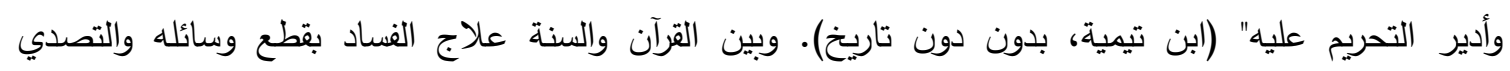

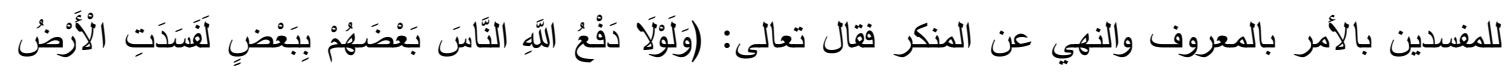

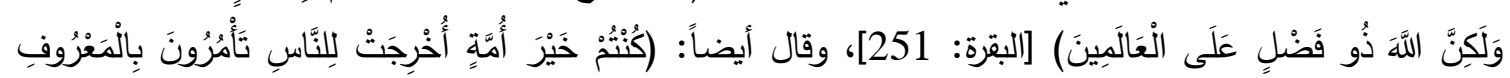

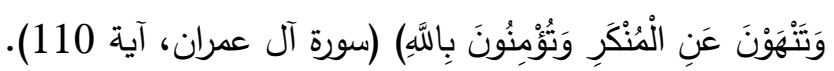

4-الضوابط الشرعية لمحاربة الفساد -

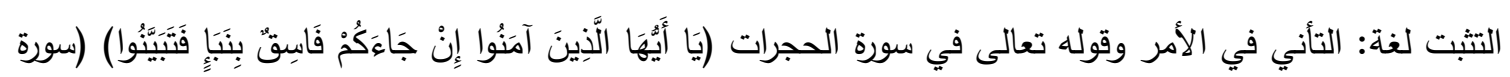

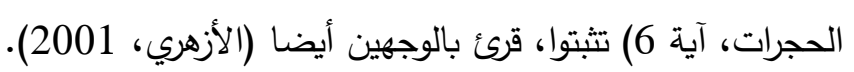

التثبت في الثرع: التبين وهو تطلب البيان وهو ظهور الأمر والتثبت التحري وتطلب الثبات وهو الصدق (ابن عاشور ، 2001). 
لا يجوز للمسلم أن يرمى شخصاً فرداً، أو جماعة، ومؤسسة بالفساد من غير تثبت وتحقق، وذلك امتثالا لقوله

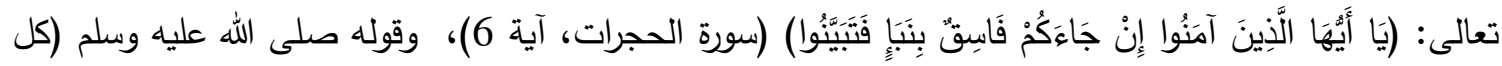

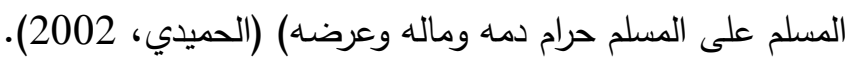
والاتهام بالفساد إذا صدر وشاع بين الناس من الصعب تداركه إذا تبين خطأه ويترك آثاراً سيئة على المتهم به، ولذلك نهى الإسلام عن الاتهام من غير تثبت، وهذا يدخل في القاعدة الفقهية " المنع أسهل من الرفع" (الحنبلي،

إنَّ منهجج التثبت في القولِ والنقلِ والسماع، لا يستغني عنه مسلمُ مهما كان مستواهُ من العلم الثقافة. فالتثبت في الأمور كلها دليل على حسن الرأي وقوة العقل، فمن تحقق وعلم كيف يسمع، وكيف ينقل، وكيف يعمل، فهو الحازم المصيب، ومن كان غير ذلك، فمآله الندامة والحسرة. فالمسلم محاسبّ على كلمة يقولها، وصدق الله وله العظيم القائل:

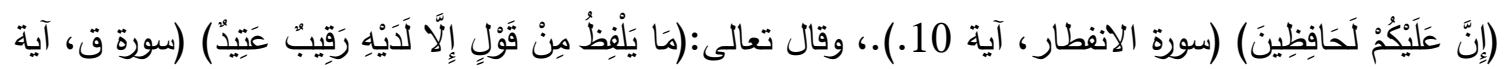

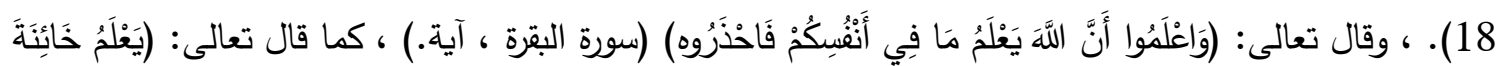

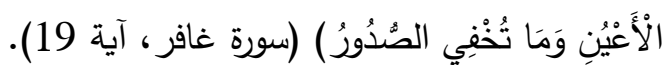

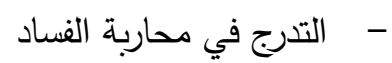

التدرج لغة: (تدرج) مطاوع درجه وإليه تقدم شيئا فثيئا وفيه تصعد درجة درجة (الدعجم الوسط، باب الدال، 10 /

التدرج في الثرع: معنى التدرج في الثرع نفس المعنى اللغوي ويقصد به عدم إكمال العمل دفعة واحدة حيث جاء الثراء في بداية الهتهد: (ومن التدرج عدم الإكثار في الحصة الواحدة حتى يكون أدعى للاستيعاب فالإمام مالكك رحمه الله

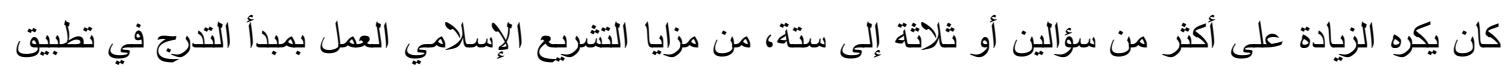

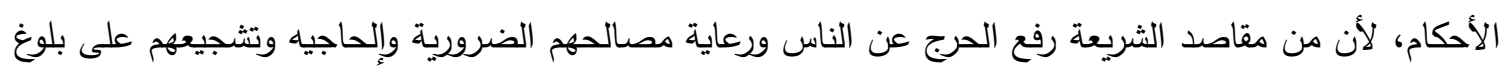

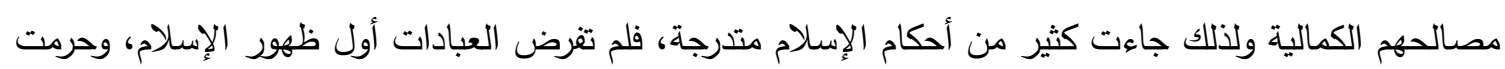

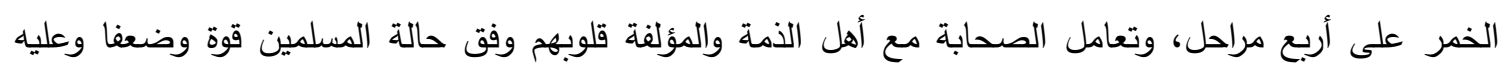

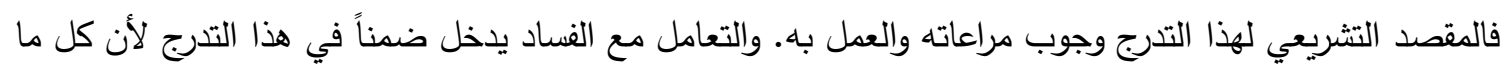

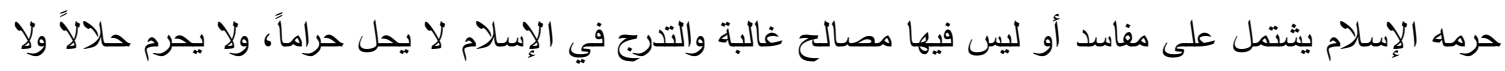

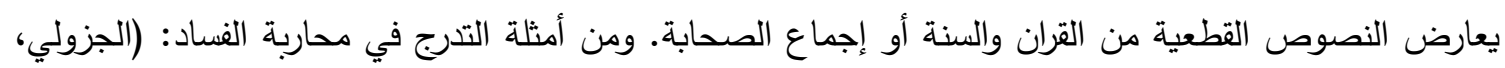

أ- إصلاح النفس: فلا يمكن لمجاهر بفساد أن يدعو غيره للإقلاع عنه أو أن يدعى محاربته، وفاقد الثيء لا

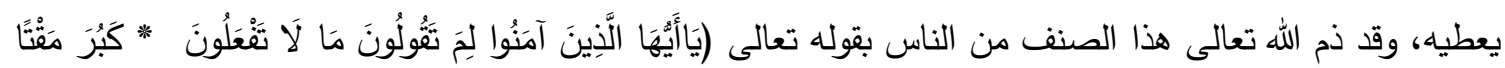

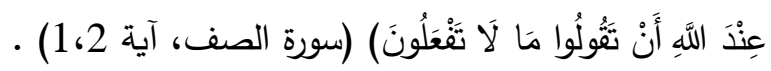

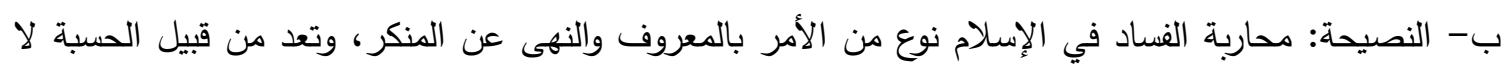

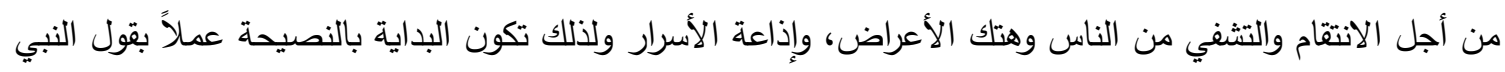

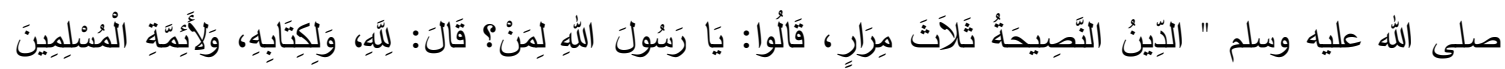

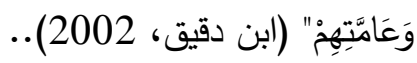

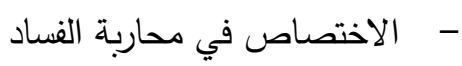

الاختصاص لغة: في المعجم الوسيط: اخْتُصّ فلان بالثيء: انغرد. فيكون الاختصاص نسبة إلى مصدر هذا

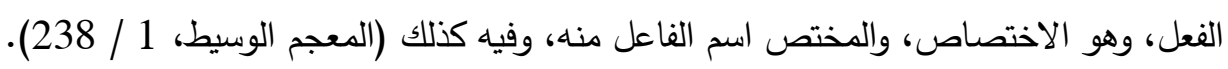


وفى لسان العرب الاختصاص معناه تقرد بعض الثيء بما لا يشاركه فيه بالجملة وذلك خلاف العموم والتعميم

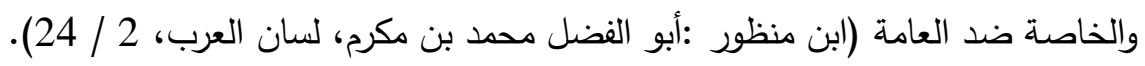
الاختصاص في الاصطلاح: لا يخرج الاختصاص في عبارات الفقهاء عن المعنى اللغوي فقد عرفه علماء الأصول

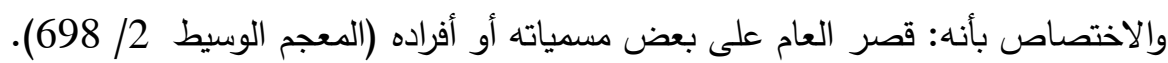

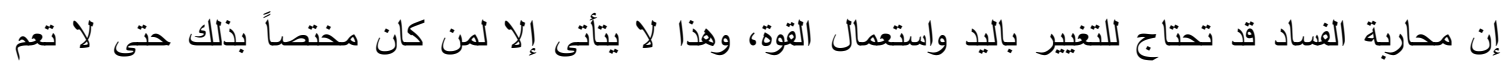
الفوضى، ويحدث الإفتيات على حقوق الأولياء، وأولى الأمر وحتى بذل النصيحة تكون مقبولة، وأكثر تأثيراً عندما تصدر ممن له ولاية على الثخص الذي بذل له النصيحة. وفيما يلي نماذج من حالات الاختصاص في محاربة الإني الفساد: - (الف - من له عليه ولاية، كالزوج على زوجته، والوالد على ولده، والسيد على عبده والرئيس على مرؤوسيه، والحاكم على رعيته - الشريك مع شركائه في العمل أو التجارة أوغيرها.

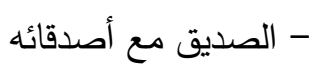

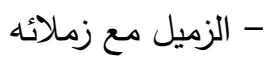
- الاعية فيمن يخاطبهم

ويجب مراعاة التسلسل في الاختصاص، مثلاً لا يجوز لمرؤوس أن يتجاوز رئيسه المباشر ويثكو الفساد لرئيسه

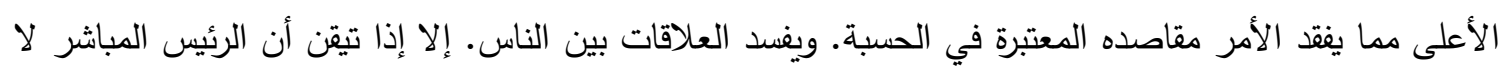

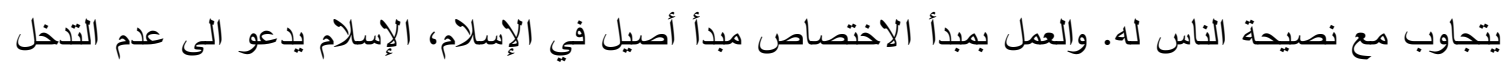

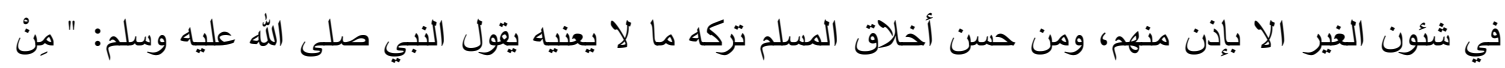

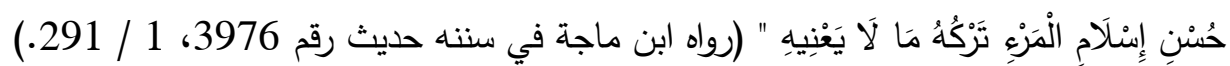
5- دور الفقهاء والعلماء في محاربة الفساد الفقيه لغة: هو العالم والعارف. واصطلاحاً: هو من عنده علم بالأحكام الشرعية عن اجتهاد أو تقليد (المعجم الوسيط 2 / 698). محاربة الفساد مسؤولية مشتركة بين جميع أفراد ومؤسسات المجتمع، وهي من أعمال الاحتساب، التي يثاب عليها

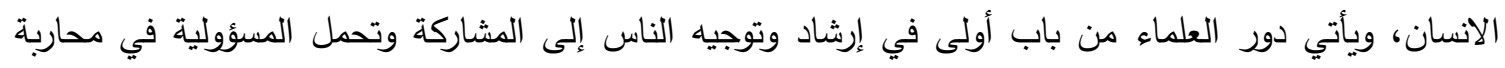

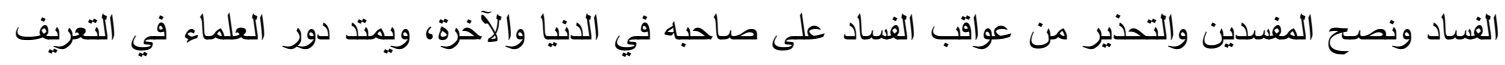
بالفساد وصوره ووسائل الوقاية منه، وطرق محاربته. ولمكانة العلماء في المجتمع يجب عادئ عليهم بذل النصح لوانلاة الأمر من الحكام والمسؤولين في تحمل مسؤولياتهم تجاه الفساد والبعد عنه ومحاربته ووقاية المجتمع منه بإزالة الأسباب. والأصل في قيام العلماء بهذا الدور تحمل الأمانة التي حملوها-أمانة العلم (الجزولي، 2015)

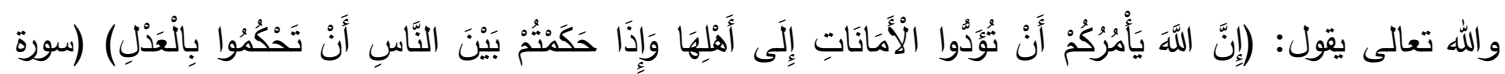

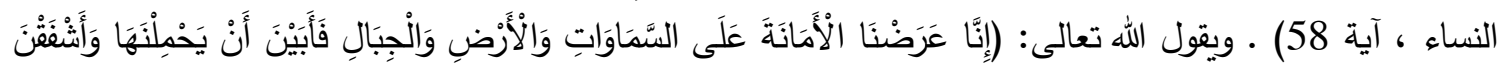

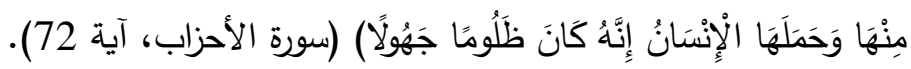
وأهم دور للعلماء محاربة الفساد هو القدوة كوقد سبق الكلام حول هذا الأمر عند الحديث عن إصلان إنهان النفس ولذلك كان الخلفاء الراشدين والصحابة من بعدهم قدوة للناس في إصلاح النفس والبعد عن الفساد قبل دعوتهم لمحاربته. وهذا الخليفة الأول أبو بكر الصديق رضى الله عنه يخطب الناس يوم بيعته (إذا رأيتم فيّ اعوجاج فقومونى). وأخذ عمر بن الخطاب (رضى الله عنه) حصة ابنه عبد الله من الثياب وإضافتها لحصته حتى يصنع بها 
جلباب يناسب طوله، ولا يميز نفسه عن الناس بأخذ زيادة على حصته. لله درك ياعمر وصحابة رسول الله ،

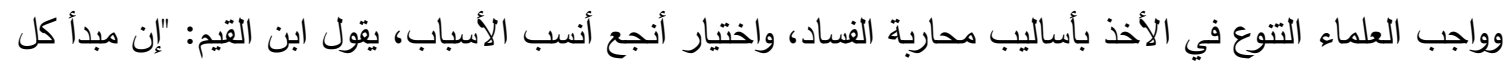

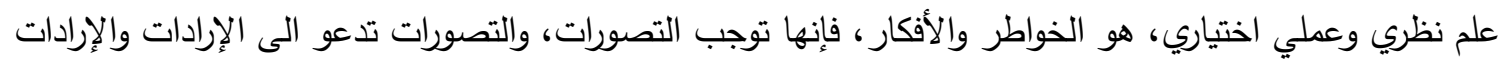

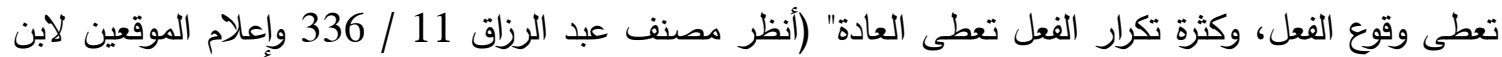

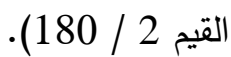

6- بعض نظريات الثريعة الإسلامية في محاربة الفساد المالي - نظرية تصرف الإمام على الرعية منوط بالمصلحة :

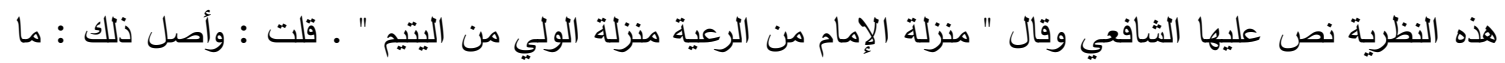

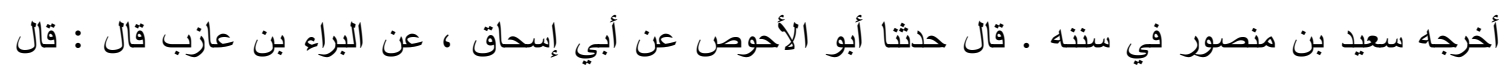

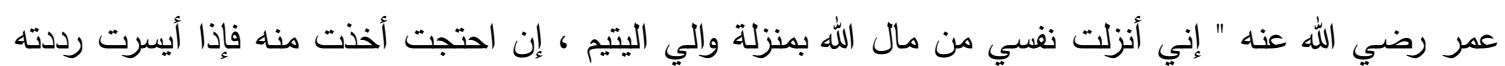

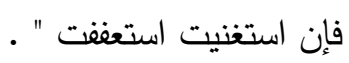

- نظرية تقديم المصلحة العامة على المصلحة الخاصـة: أي أن المصالح العامة إذا كانت ضمن حقوق الله فإنها إذن غير قابلة للإسقاط أو الإهمال بحال، شأننا فيها مثل

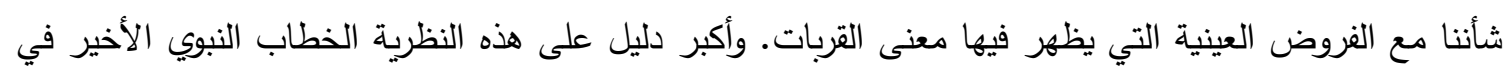

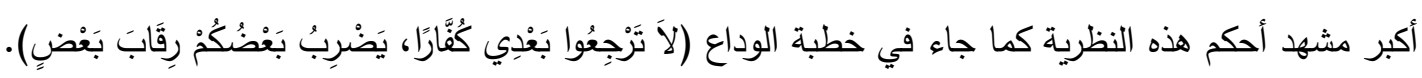

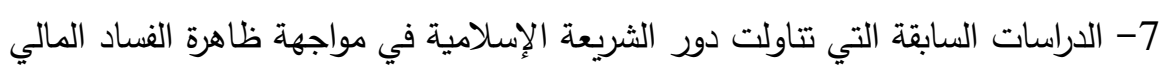
سعت دراسة الدحروق (2016) إلى تحقيق جملة من الأهداف أهمها، بيان شمول الشريعة ودورها في معالجة

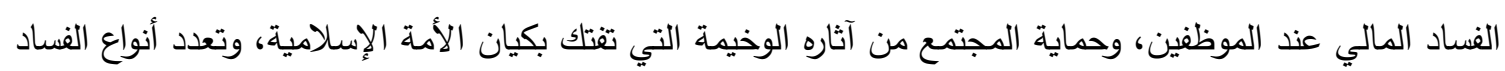

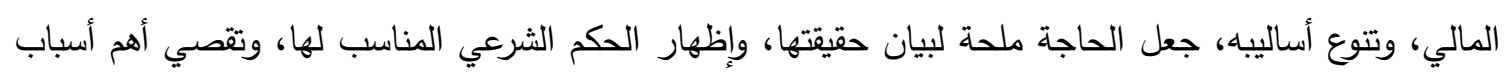
استشرى ظاهرة الفساد المالي عند الموظفين، ومحاولة الحد من انتشارها. وقد ارتكز البحث على المنهج الاستقرائي

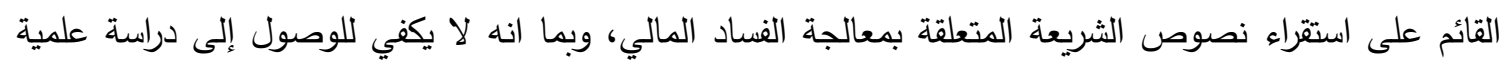
متقنة، كما لا يجلب كبير فائدة للباحث؛ فاقتضى الأمر أن ينضم إليه المنهج التحليلي بغية تحليل القضايا الأساسية

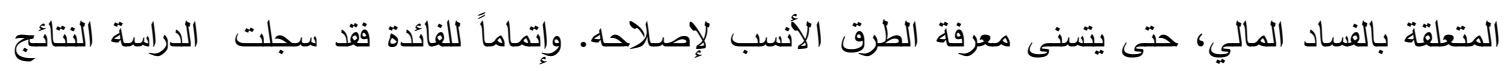

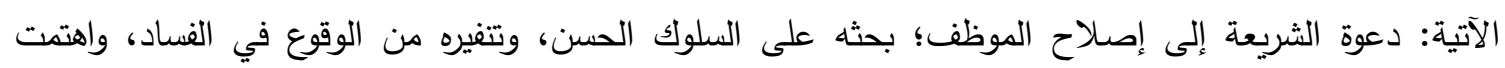

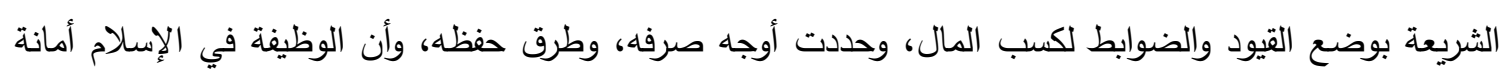

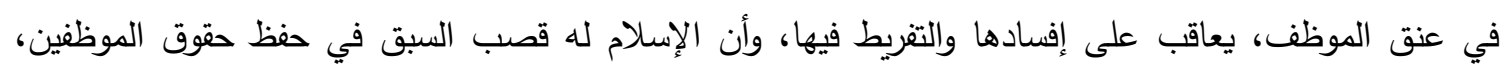
وتوفير الأمن الوظيفي لهم، والبعد بهم عن الانحراف والزلل.

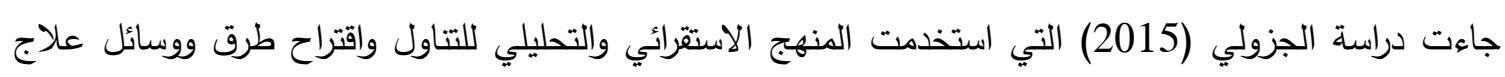
الفساد المالي من منظور الثريعة الإسلامية والذي يعتبر في حد ذاته حديث قديم جديد تتاوله الإسلام في مصادر

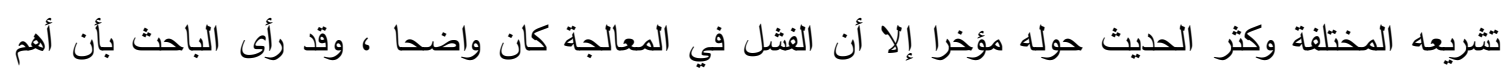

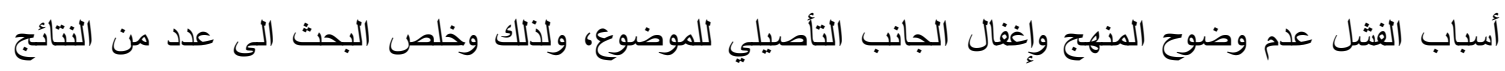

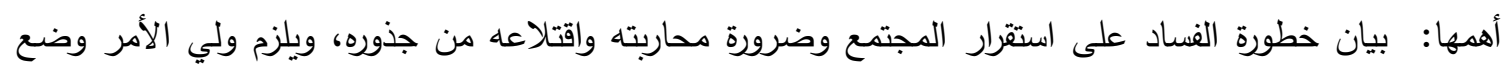
التشريعات اللازمة لمحاربة الفساد، مع ضمان الفمان تنفيذها.

كما هدفت دراسة ربابعة (2015) إلى توضيح دور السنة النبوية في مكافحة ظاهرة الفساد المالي التي تفشت في

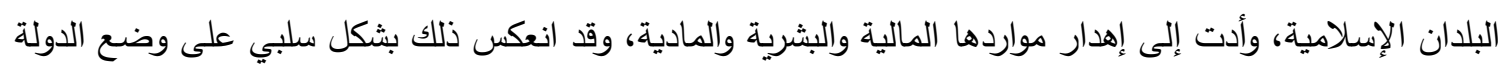


المالي، وعلى أوضاع الأفراد الذين يعيشون في كنفها، فتتاول دور السنة النبوية في منع الفساد في كل من جباية

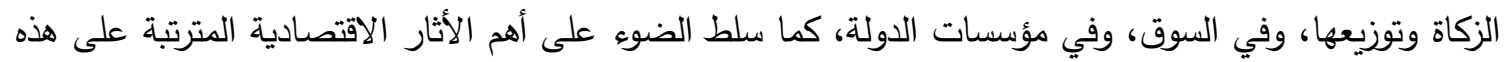

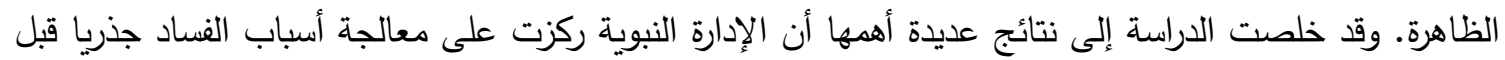

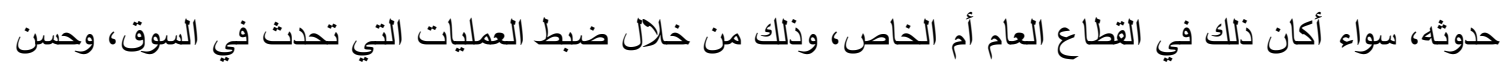
اختيار الموظفين في القطاع العام، ومراقبتهم ومحاسبة المخطئ منهم، ووضع تشريعات تمنع الفساد في جباية الزكاة، والإيرادات العامة، وتمنع الفساد في إنفاقها. هدفت دراسة الغامدي (2014) إلى التعرف على مظاهر محاربة السنة النبوية للفساد المالي (جمعا ودراسة). وجاءت الدراسة في مقدمة وتمهيد وستة مباحث. أما المقدمة وفيها افتتاحية للدراسة وبيان خطتها. وأما التمهيد

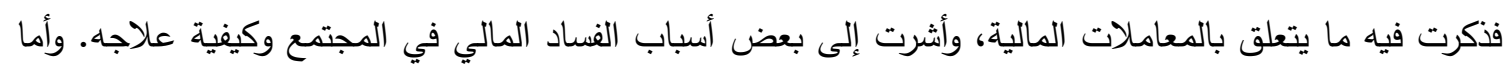

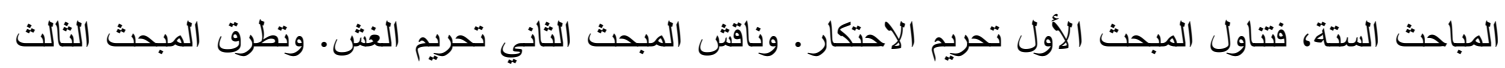

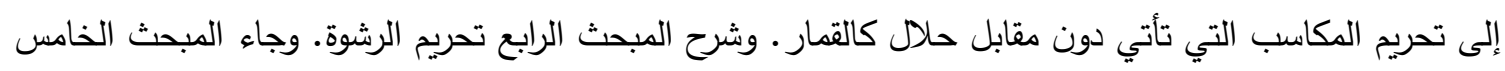

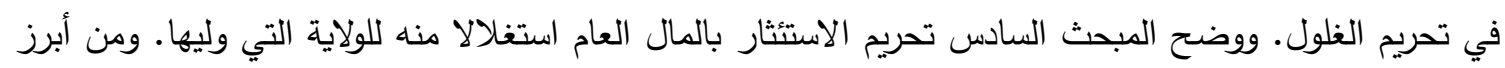

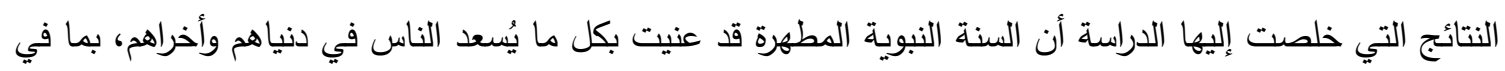

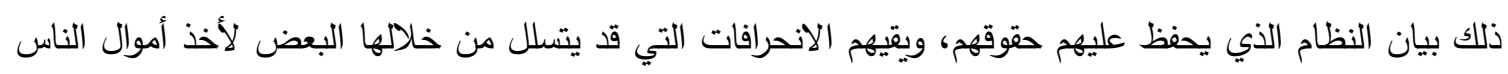
بالباطل. وأوصت الدراسة بضرورة عناية الباحثين ومراكز الدراسات والأبحاث والمؤسسات العلمية بتقريب السنة النبوية بين يدي الأمة، وخاصة في الموضوعات التي تلامس معاشهم وتتظيم حياتهم. الإطار العملي للاراسة المقابلات شبه المقنتة تعتبر المقابلة في حد ذاتها محادثة جادة بين شخصين المفحوص والأخصائي القائم بالمقابلة يحاول أن يفهم Semi-structured المفحوص ويحصل على معلومات معينة ، وقد اعتمد الباحث طريقة المقابلة شبه المقننة interview

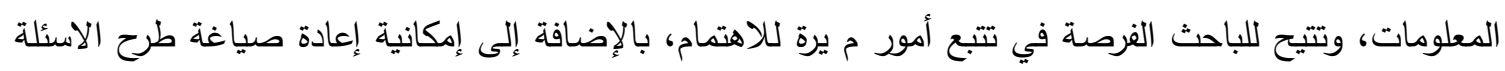
بطريقة تسهل على المشارك فهم السؤال. ولجمع البيانات في هذه الدراسة تم عمل مقابلات فردية شبه مقننة مع عدد من المسؤولين في كل من وزارة الأوقاف والثؤون الإسلامية وهيئة الفتوى والتشريع، حيث تم طرح عدة تساؤلات عليهم وفي هذه المقابلات تم طرح أسئلة ركزت على جوانب متعددة ذات علاقة بموضوع الدراسة ، ولضمان تغطية هذه الجوانب تم إعداد دليل لتللك

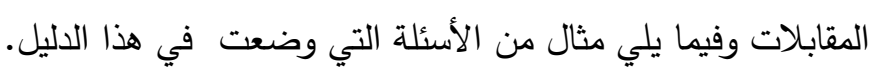

جدول (1)

أمثلة لأسئلة المقابلة التي أجريت مع عدد المسؤولين في كل من وزارة الأوقاف والثؤون الإسلامية وهيئة الفتوى

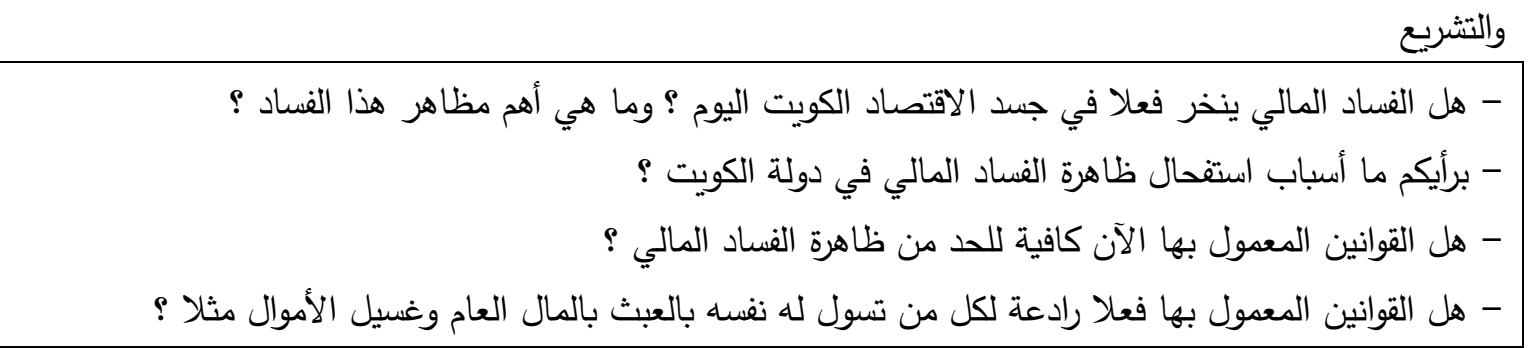


- أين دور رجال الدين حول كل ما يجري من قضايا فساد مالي سواء من غسيل أموال ونهب للمال

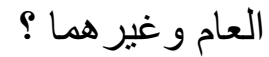

تراوحت مدة المقابلات بين ( 35 - 25 ) دقيقة؛ بحيث تم تغطية جوانب الدراسة، وهذه المقابلات أجريت في مكان

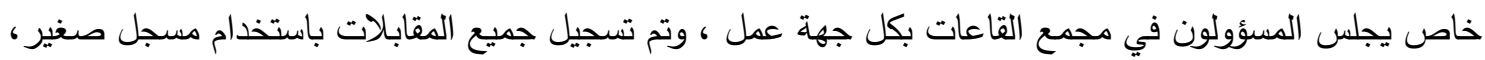

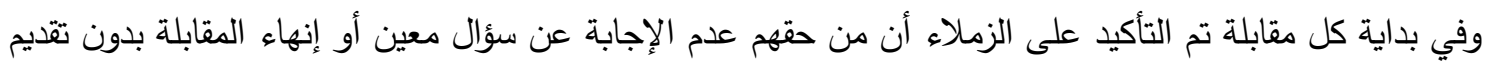

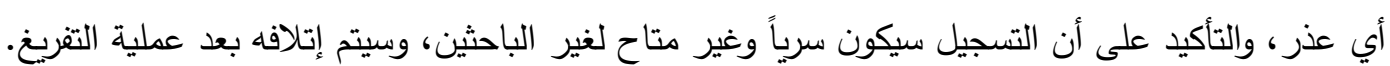

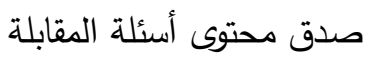
قام الباحث بعرض أسئلة المقابلة على عدد من أعضاء هيئة التدريس في جامعة الكويت، للتأكد من سلامة صياغة الاسئلة لغويا وموضوعيا وإبداء أية آراء أو ملاحظات حولهات التهاء عرض لنتائج المقابلات مع عدد من المسؤولين ممن لايهم باع ودراية وخبرة في مجال قضايا الفساد المالي بدولة الكويت الكيت

السؤال الأول: هل الفساد المالي ينخر فعلا في جسد الاقتصاد الكويت اليوم ؟وما هي أهم مظاهر هذا الفساد ؟

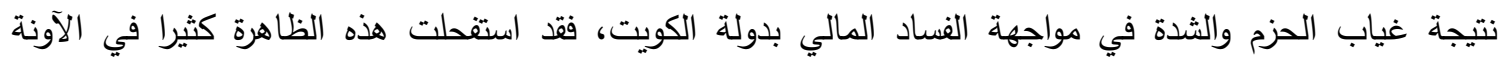

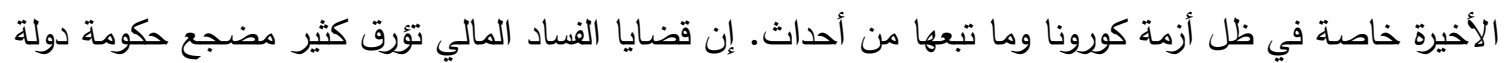

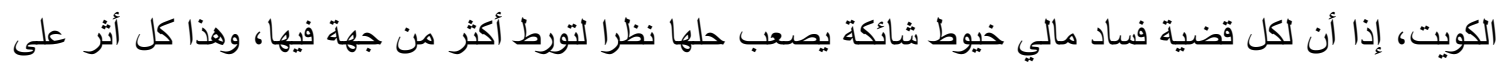

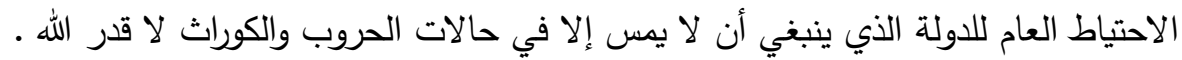

أما أبرز مظاهر الفساد المالي بدولة الكويت فإنها تتمثل في الآتي:

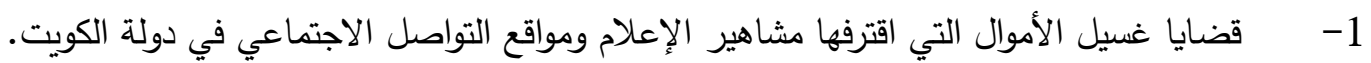

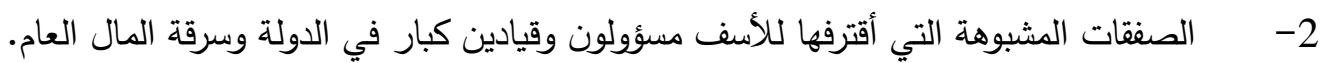

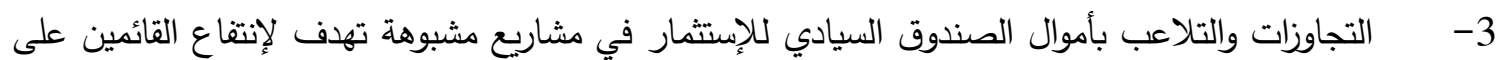

4- - التحويلات المالية الضخمة الواردة والصادرة.

5- النصب العقاري على المواطنين حيث يتم عرض عقارات، أراض وشقق وبيوت، خارج الكويت من خلال

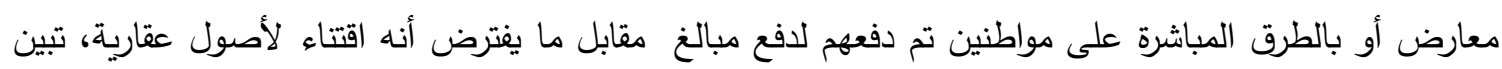

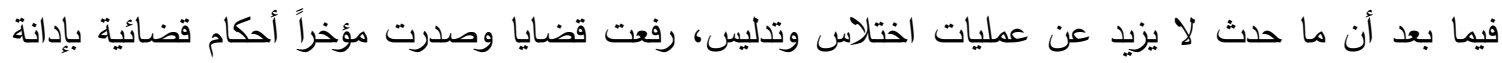
المختلسين من مواطنين ووافين بالين

6- ضضايا تتعلق بإستثمار أموال المؤسسة العامة للتأمينات الإجتماعية (أموال التقاعد) التي إتهم بها المدير

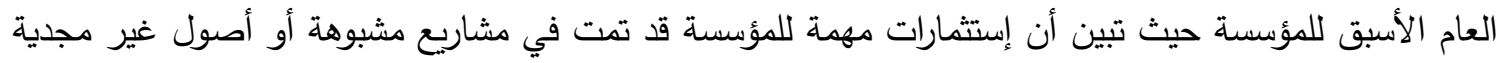

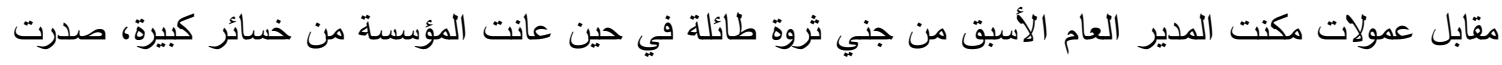

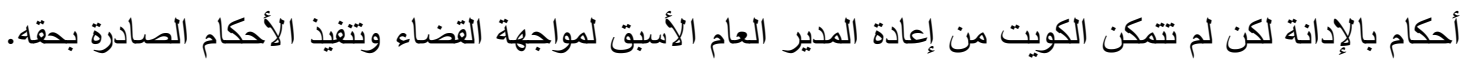

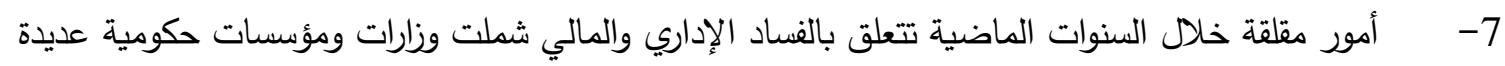

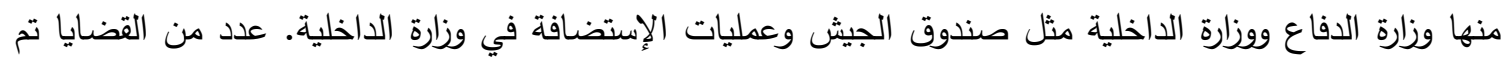
تحويلها إلى النيابة العامة وهي مازالت قيد التحقيق والتداول في القضاء. 
8- ما برز خلال أزمة وباء كورونا المستجد من قضايا تمثلت في التجارة بالبشر واتهام قياديين في وزارة الداخلية وهيئة القوى العاملة بالتورط مع المتاجرين بالبشر وتقاضى أتاوات من العمالة الوافدة الفقيرة وتجاوز قانون

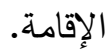

9- - القضايا المتعلقة بالرعاية الصحية حيث يتم التلاعب بعمليات شراء الأدوية أو إرسال عدد من المرضى

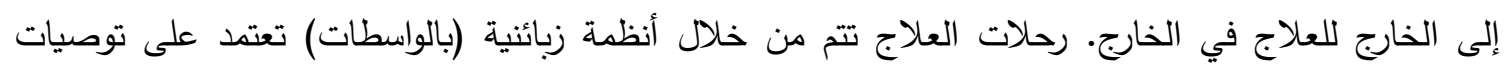
أعضاء في مجلس الأمة. في بعض هذه الحالات، يتم إرسال المرضى مع مرافقين وتستمر رحلات العلاج لمدد

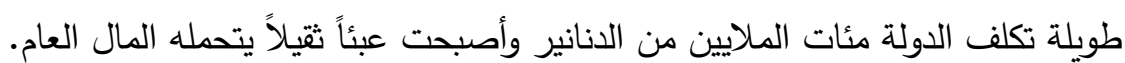
10- خلال السنتين الماضيتين، توسعت قضايا الفساد لتصل إلى قطاع التعليم مع اكتثاف مئات الشهادات الجامعية المزورة والصادرة من جهات مشكوك فيها في بلدان عربية وأجنبية. لا شك أن هذه الممارسات والتي قادها لـانيا

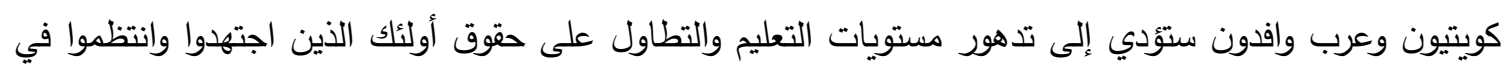
جامعات مرموقة من سبيل التحصيل العلمي. كما أن تخريب قطاع التعليم مكن الكثير من المزيفين من إحتلال مواقع مهمة وأساسية في مختلف الجهات الحكومية بما ينعكس سلبيُا على أداء هذه الجهات.

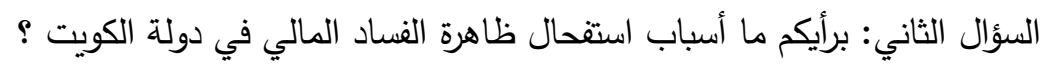

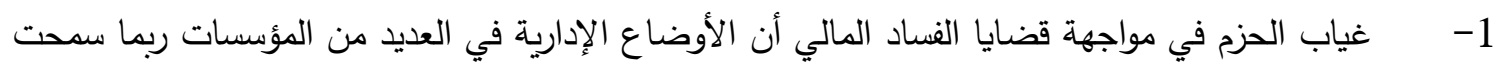
للقائين عليها بالتربح وجني الثروات دون مواجهة أنظمة رقابية ومحاسبية صارمة تحول دون التجاوز على الأموال التي تدار من قبلهم. 2- - أغلب المتهمين بقضايا الفساد غالبا ما يخرجون بكفالات مالية زهيدة مما يثجعهم ويشجع الآخرين على السير في هذا الطريق الفاسد والخطير. 3- وجود خلل في المنظومة القضائية والترتيبات القانونية مع بلدان عديدة مثل بريطانيا وعدد من دول أمريكا اللاتينية حالت دون رد الحقوق القانونية للبلاد وتتفيذ مقتضيات العدالة بحق من صدرت بحقهي التهم الأحكام

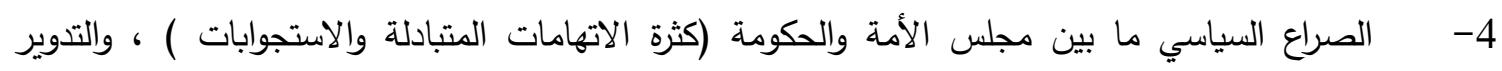
الوزاري كله تسبب بحالة من الفوضى واللااستقرار وبالتالي الانشغال عن مواجهة قضايا الفساد وتعطيل عجلة التمية في البلاد. السؤال الثالث: هل القوانين المعمول بها الآن كافية للحد من ظاهرة الفساد المالي ؟ هل هي فعلا رادعة لكل من

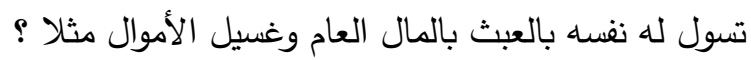
أجمع أغلب ممن أجرى الباحث مقابلات معهم بأن القوانين المعمول بها الآن هي غير كافية للحد من ظاهرة الفساد

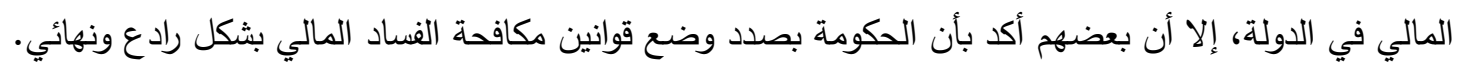
لقد أصبحت متابعة أخبار الفساد أو الفضائح المالية على وسائل التواصل الاجتماعي الهم الأول للكويتيين أو للكثير

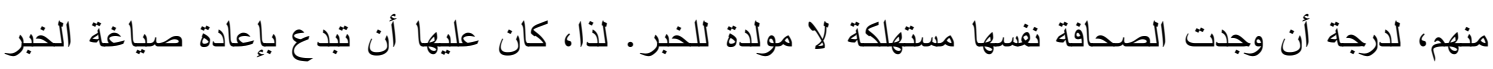
أكثر من مقدرتها على تقديم الخبر الجديد. وقد أصاب الذين تمت مقابلتهم الضجر من أنفهه كمتابعين لأخبار

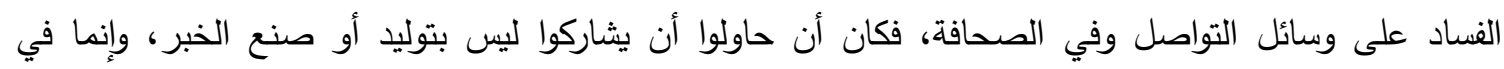
تحليله. كما أوضح أفراد عينة الدراسة بأن في دولة الكويت بشكل عام يظهر ما يلي: 1- إن التدين مظهر أكثر من جوهر اوضئ 2- 2 - عدم الاطمئنان للمستقبل 


\section{3- يبقى الفاسدون قلة

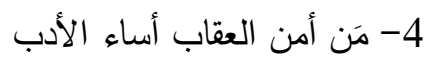

الحقيقة أن أسباب الفساد تزيد على ما ذكر، خاصة أنها الأسباب المذكورة تصلح لتفسير الفساد في أي مجتمع. لذا،

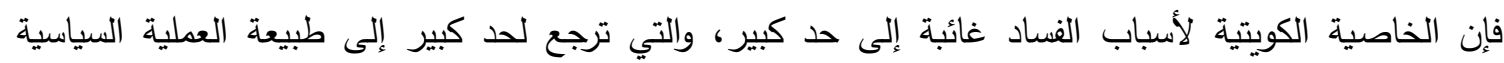

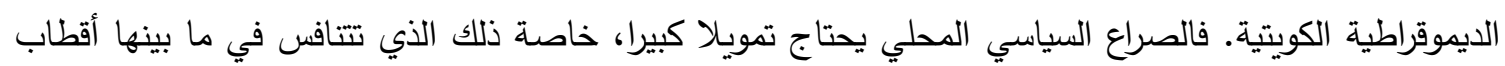
داخل الأسرة الحاكمة. كما تتتافس كذلك قوى أخرى تجمع بين النفوذ المالي والسياسي. وصراع هذه الأقطاب يبدأ بتمويل الحملات الانتخابية لدعم مرشحين متحالفين معهم، ويستمر إلى نهاية دورة المجلس، لكون صراع بعض لهض الأقطاب وأصحاب النفوذ يستمر للتأثير في قرارات المجلس المؤثرة في مصالحهم. ويستمر تتافس أقطاب في الأسرة

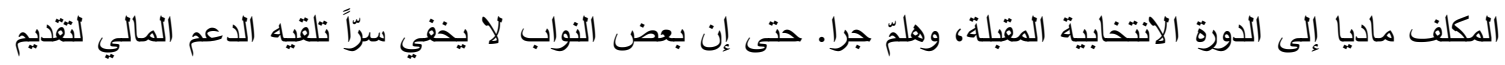
الولاء من ناحية ولنيل الولاء من قاعدته الانتخابية من ناحية اخرى.

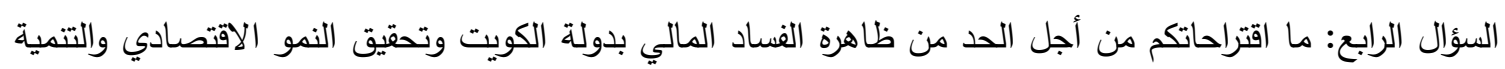

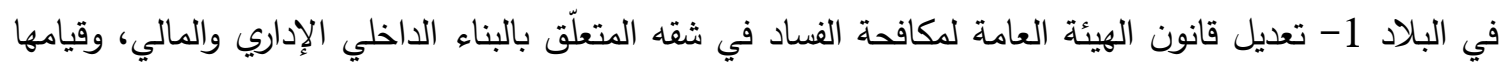
بواجباتها كما رسمها قانون إنشائها.

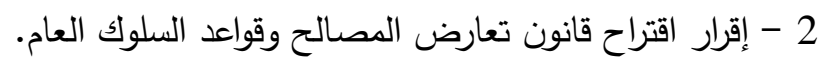

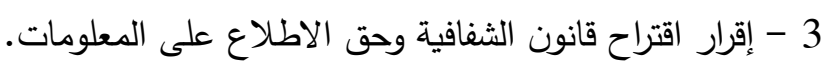
4 - الإسراع في وضع وتتفيذ استراتيجية وطنية لمكافحة الفساد. 5 - إقرار اقتراح قانون التعيين في الوظائف القيادية.

6 - تطوير الديموقراطية الكويتية، مثل إقرار اقتراح قانون الهيئة العامة للديموقراطية. 7 - المجتمع المدني: السماح له بالعمل بحرية في دعم جهود تعزيز النزاهة ومكافحة الفساد. - إشراكه في (رؤية الكويت الجديدة 2035). 8- تطوير التشريعات واللوائح (التأمينات، تضخم أرصدة نواب). 9- إنفاذ القانون لإرساء العدل.

السؤال الخامس: أين دور رجال الدين حول كل ما يجري من قضايا فساد مالي سواء من غسيل أموال ونهب للمال العام وغيرهما ؟ طالب المسؤولون في وزارة الأوقاف والثؤون الاسلامية بدولة الكوبت بضرورة تطبيق أساليب المواجهة الإسلامية لكل صور الفساد المالي في الدولة خاصة بعد الثكوى من شيوع الفساد في أكثر من جهة وعدم قدرة أساليب

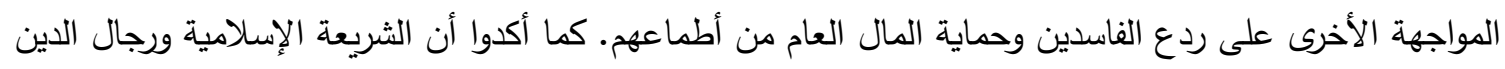

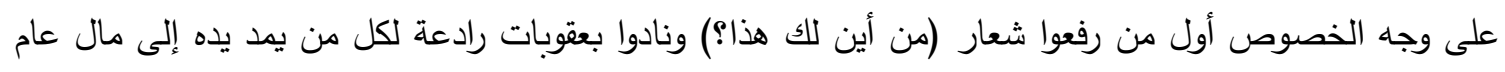

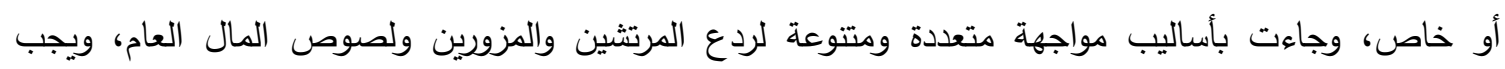

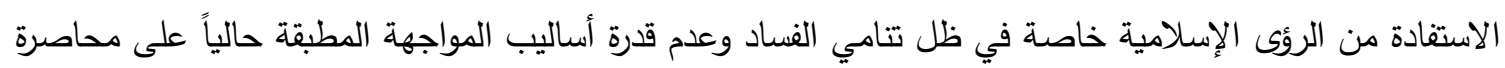
الفاسدين وتطبيق العقوبات الرادعة عليهم. التوصيات والمقترحات بناء على نتائج البحث، فإن الباحث يوصي ويقترح ما يلي: 1- تفعيل الخطاب الديني بثكل أكثر فاعلية في كافة وسائل الإعلام والمنابر بالمساجد والمؤسسات الدينية لفئية حول خطورة الفساد المالي على الفرد والمجتمع وتحذير الناس من عقوبة الله بحق كل مفسد. 
2- تفعيل دور رجال الدين والاستعانة بهم في كل محاولات ومساعي الحكومة للتصدي لظاهرة تفشي الفساد المالي

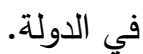
3- الاحتكام بمبادئ الشريعة الإسلامية في كافة التعاملات المالية للدولة والصقفات والاتفاقات وما إلى ذلك.

إبراهيم، إبراهيم عبد الرحمن. (2015). "دور التشريع في محاربة الفساد: السودان نموذجا"، مجلة العلوم الإنسانية،

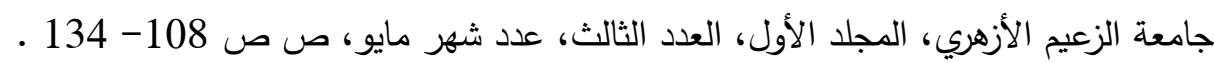

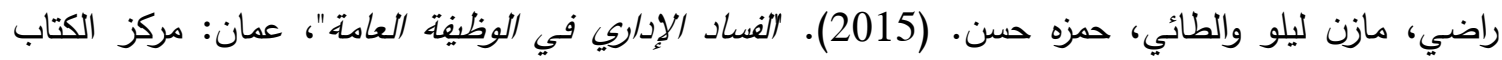

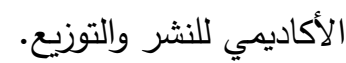

فرحان، خالد أحمد. (2012). "ظاهرتي غسيل الاموال والفساد المالي واثرهما على الاقتصاد العراقي : دراسة حالة بعد الاحتلال الأمريكي للعراق في 9-4-2003"، مجلة المنصور، بغداد، المجلد الأول، العدد السابع

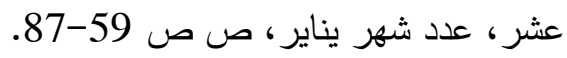

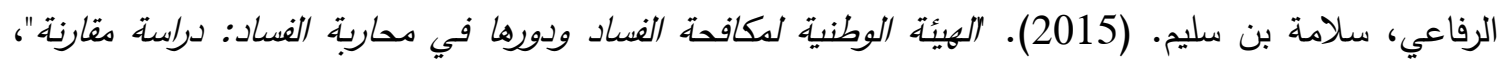
الرياض: مكتبة القانون والاقتصاد.

جمعة، صفاء فتوح. (2014). "مسؤولية الموظف العام في إطار تطبيق نظام الإدرة الإلكترونية"، الدنصورة-

$$
\text { مصر : دار الفكر والقانون • مصناف }
$$

شمري، هاشم محمد. (2011). الفساد المالي والإداري وآثاره الاقتصادية والاجتماعية"، بيروت: دار اليازوري

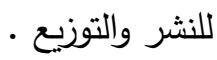

اسماعيل، علي سيد. (2019). أبحاث دعاصرة في الاقتصاد الاسلامي والدعاملات المالية والدصرفية: الفكر

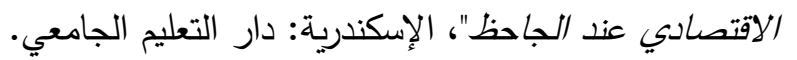

عبد المجيد، محمود عبد المجيد. (2018). الفساد: تعريفه وصوره وعلاقته بالأنشطة الإجرامية الأخرى"، القاهرة:

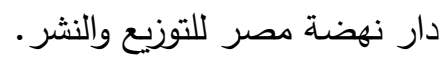

تثرير الاتجاهات الاسترتيجية". (2005). القاهرة: مركز الدراسات السياسية والاستراتيجية بالأهرام.

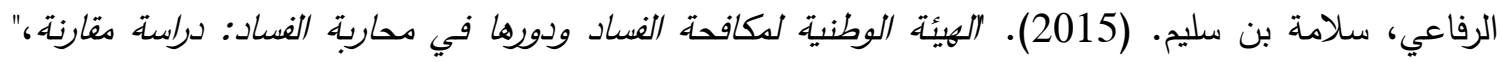

$$
\text { الرياض: مكتبة القانون والاقتصاد. }
$$

الثريف، محمد بن عبد الله. (2016). "النزاهة في مواجهة الفساد: تجربة المدلكة العربية السعودية"، الرياض: دار

$$
\text { العبيكان للنشر والتوزيع. }
$$

عليمات، خالد عيادة. (2020). الفناد وانعكساته على التنمية الاقتصادية : دراسة حالة الأردن"، عمان: دار

$$
\text { الخليج للنشر والتوزيع. }
$$

اسماعيل، محمد صادق. (2014). "الفساد الإداري في العالم العربي: مفهومه وأبعاده المختلفة"، القاهرة: المجموعة

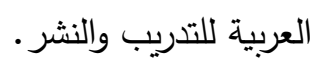

دغمش محمد سامر • (2018). استراتيجيات مواجهة الفساد المالي والإداري والدواجهة الجنائية والآثار المترتبة على الفساد المالي: دارسة مقارنة"، عمان: مركز الدراسات العربية للتشر والتوزيع.

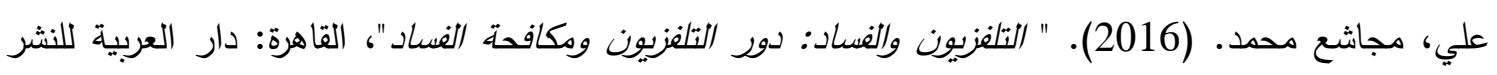
والتوزيع. 
دودين، أحمد يوسف والدليمي، حمد فواز • (2011). الازمات المالية الدولية والعالمية"، عمان: دار جليس الزمان.

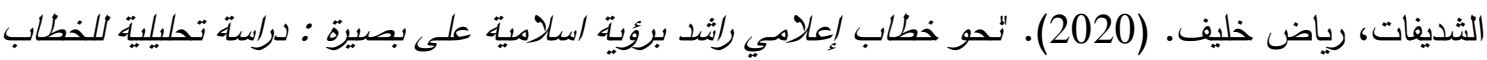
الإعلامي الدعاصر"، عمان: دار الجنان للنشر والتوزيع. الكبيسي، عامر محمد. (2000). "الفساد الإداري رؤية منهجية للتشخيص والتحليل والمعالجة"، المجلة العربية للإدارة، المجلد الأول، العدد الثرين، عدد شهر يونيو، ص صل صل 85-122. الغامدي، محمد بن علي. (2014). "مظاهر محاربة السنة النبوية الثريقة للفساد المالي"، مجلة كلية الثريعة صدية

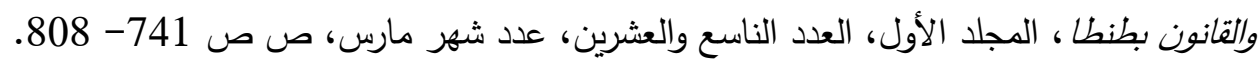

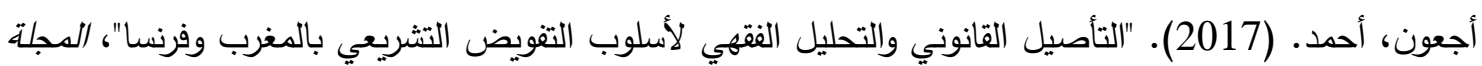

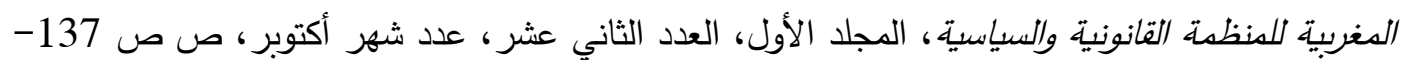
.176

أحمد، أشرف السيد. (2016). "أثر الفساد على النمو الاقتصادي في مصر"، مجلة البحوث التجارية ، جامعة الزقازيق، كلية التجارة، المجلد التاسع والثلاثين، العدد الأول، عدد شهر يناير، ص صل ص 257- 279 279 ـ ادريس، عبد الفتاح محمود. (2013). "مكافحة شائبة الفساد الإداري في المجتمعات المعاصرة: دراسة مقارنة بين

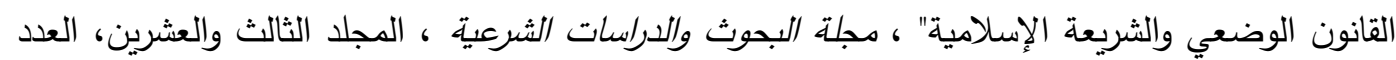

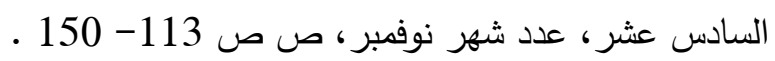

آل خليفة، لبنى علي. (2015). "الثفافية ومكافحة الفساد: دراسة حالة دول مجلس التعاون الخليجي وفقا لمؤشرات البنك الدولي للحكم الصالح في الفترة من 1996-2013 "، الدجلة الدصرية للدراسات التجارية، جامعة دالئة

المنصورة، كلية التجارة، المجلد التاسع والثلاثين، العدد الثاني، عدد شهر يناير، ص صن صن 143-164. بحار ، محمد (2016). "الإطار القانوني لمحاربة الفساد: قراءة في إتفاقية الأمم المتحدة لمحاربة الفساد

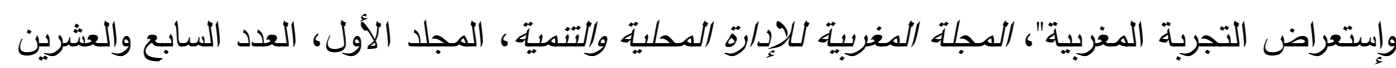

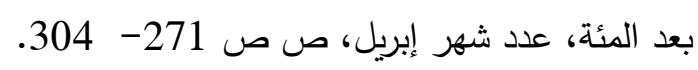

بلبال، حسناوي. (2019). "أسباب الفساد الإدارى والمالى وإستراتيجية مكافحته"، مجلة بحوث الإدارة والاقتصاد،

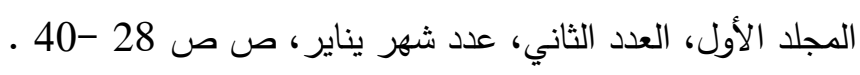

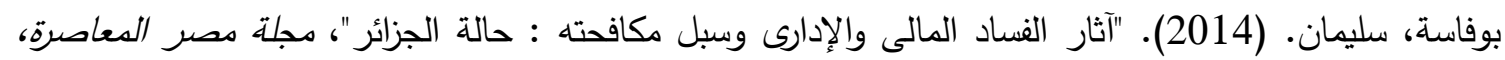

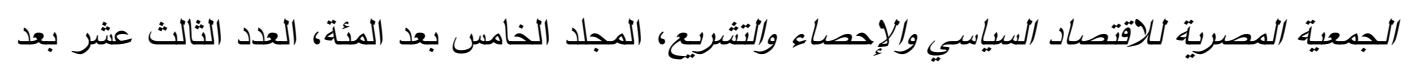

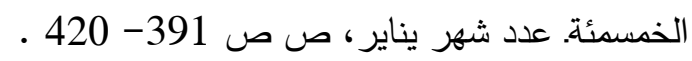

التميمي، أحمد حميد والسلامي، إبراهيم. (2018). 'أحكام قوانين الأحوال الثخصية بين الشريعة الإسلامية

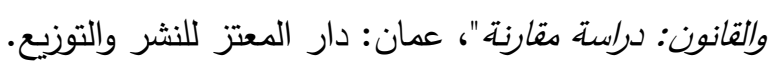

جار الله، علي محمد. (2019). كفى فسادا، الكويت: دار سما للنشر والتوزيع.

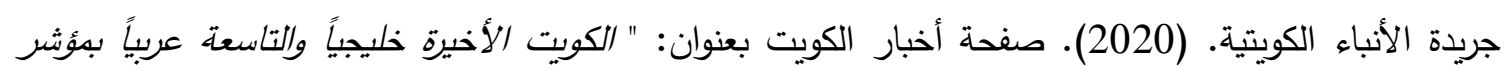

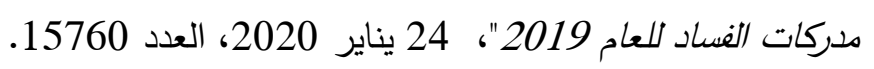

جريدة القبس الكويتية. (2018). صفحة الاقتصاد بعنوان: " الفساد يزد/د استفحالا في الكويت " 22 فبرابر 2018، العدد 15123 .

الجزولي، صديق أحمد. (2015). "محاربة الفساد: رؤية تأصيلية" ، محلة الدراسات الإسلامية ، جامعة المدينة

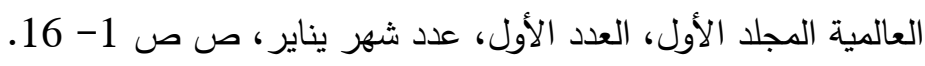


الحاج، طارق • (2008). "مظاهر الفساد الإدارى والمالى"، مجلة راح للبحوث والدراسات، مركز البحث وتطوير

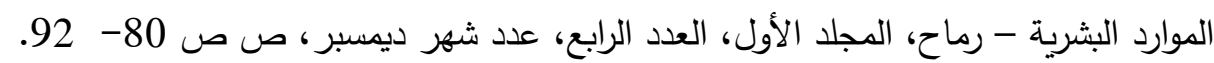

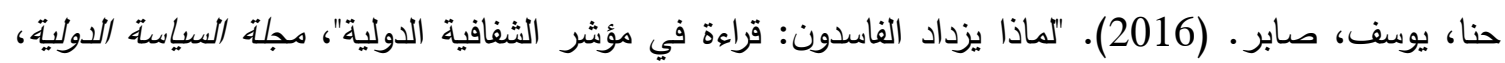
السنة الثانية والخمسين، ملحق، عدد شهر إبريل، ص ص ص 25 - 250 الخطيب، خالد راغب. (2008). "الفساد الإداري والمالي: المعضلة والعلاج تجارب بعض الدض الدول" ، مجلة رماح

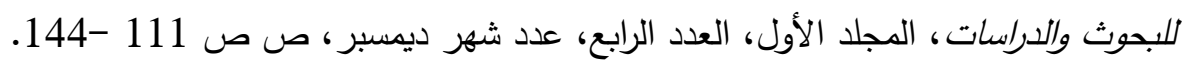

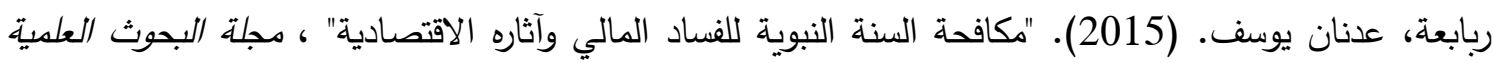

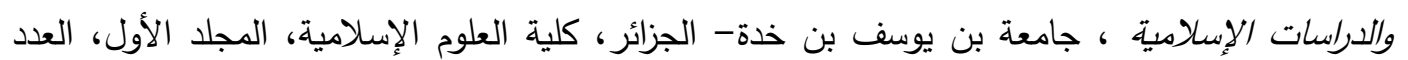

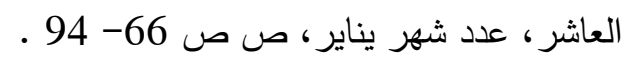

الزبيدي، خالد لفتة شاكر. (2015). "دور القضاء في مكافحة الفساد: دراسة تحليلية في ضوء القانون العراقي"،

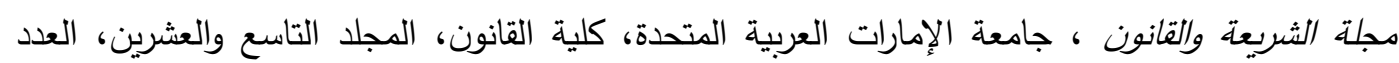

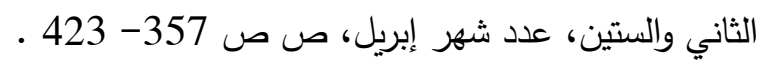

سالم، حنان محمد. (2003)." ثقافة الفساد في مصر دراسة مقارنة للدول النامية" ، القاهرة: دار مصر المحروسة. سهيلة، عبد الزهراء. (2015). "الفساد الإداري والمالي في العراق: مظاهر وأسباب ومعالجات"، مجلة الإدارة والإقتصاد، الجامعة المستتصرية، كلية الإدارة والاقتصاد، المجلد الثامن والثثلاثين، العدد الثاني بعد المئة،

$$
\text { عدد شهر مايو، ص ص ص 49 4-61. }
$$

السيد، هدى محمد. (2018). "دور القانون المصري في مكافحة الفساد المالي في الجهاز الإداري للدولة" ، مجلة

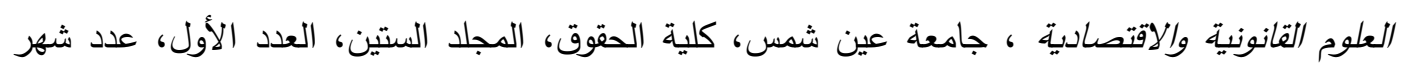

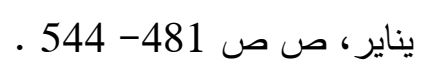

الثاشاتي، راشد إبراهيم. (2014). "نظرية العقوبة المبررة وتطبيقها في التشريع والقضاء الأردني: دراسة مقارنة"،

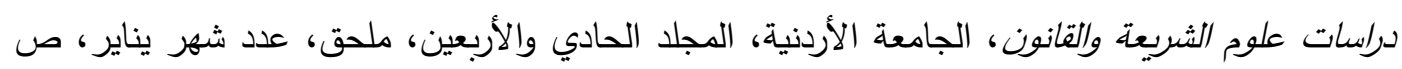

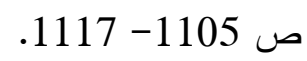

شحاتة، حسين حسين. (2011). الفساد المالي أسبابه وصوره وعلاجه، مجلة الوعي الإسلامي"، دولة الكويت،

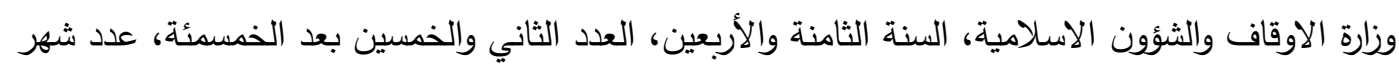

$$
\text { يوليو، ص ص ص 26-27. }
$$

شمري، هاشم. (2011). الفساد الإداري والمالي وآثاره الاقتصادية والاجتماعية"، عمان: دار اليازوري العلمية

$$
\text { للنشر والتوزيع. }
$$

صبري، عبد الرحمن. (2006). "اقتصاديات الفساد وأبجديته"، مجلة شؤون عربية، جامعة الدول العربية - الأمانة

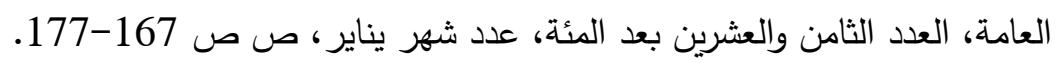

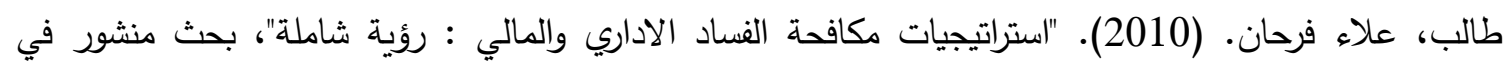

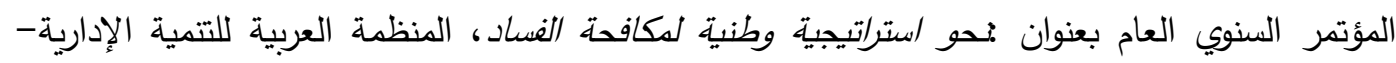

$$
\text { مصر، الفترة من 1-2 يوليو } 2010 \text {. }
$$

عبود، علي سكر • (2010). "تحليل صور وأسباب الفساد المالي والإداري : دراسة استطلاعية لعينة مختارة في

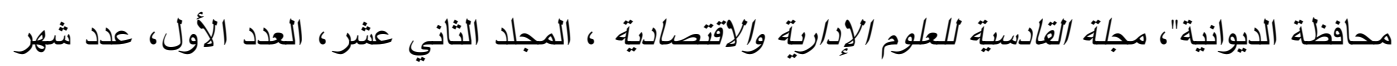

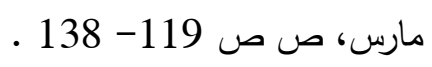


القرطبي، محمد بن أحمد. (2005). الجامع لأحكام القرآن"، القاهرة: دار الحديث للنشر والتوزيع.

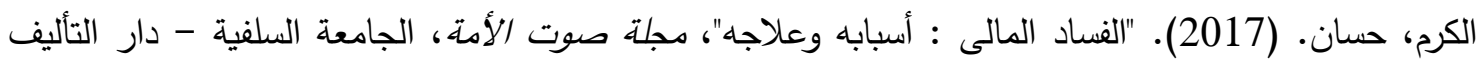

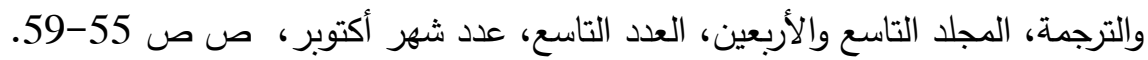

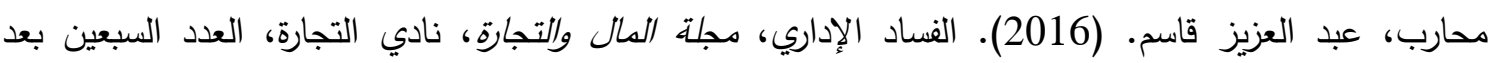

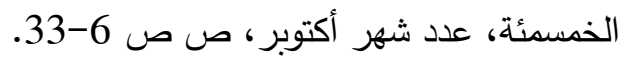

المحروق، عادل إبراهيم عبدالله . (2016). دور الثريعة الإسلامية في إصلاح الفساد المالي ، مجلة آفاق

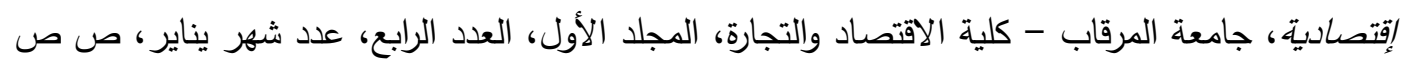

$.192-163$

محمدن، محمد عبد الله (2010). "التأصيل في الرسائل والأطروحات"، بحث منشور في الملتقى العلمي الأول بعنوان (تجويد الرسائل والأطروحات وتععيل دورها في التتمية الثاملة والمستدامة)، جامعة نايف للعلوم

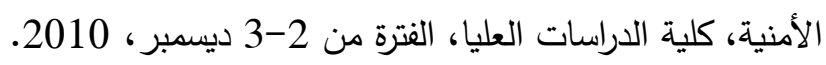

معتوق، سامية محمد. (2019). "الفساد في الدول العربية: بين مصاعب الواقع وحتمية المعالجة"، مجلة دراسات

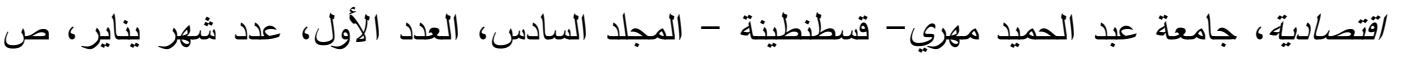

$$
\text { ص } 247 \text {-270 }
$$

المعمري، عبد الملك أحمد. (2013). "الفساد المالي والإداري أثكاله مسباته وأثره في إعاقة التنمية: دراسة ميدانية على الجهاز الحكومي لمدينة تعز"، مجلة مركز صالح عبد الله كامل للاقصاد الإسلادي، المجلد السابع

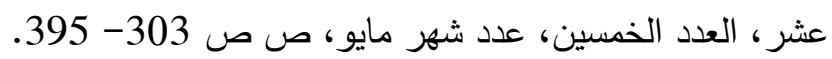

الملا، معاذ سليمان. (2020). "مكافحة الفساد وعلاقته بالتتمية المستدامة :دراسة وصفية في ضوء صاء أحكام القانون

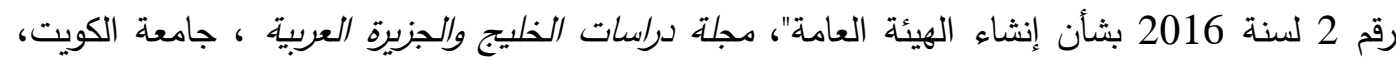
مجلس النشر العلمي، السنة السادسة والأربعين، العدد السابع والسبعين بعد المئة، عدد شهر إبريل، ص صلئه ص .453-401-401 نعمة، مناف مرزة. (2015). "الآثار الاقتصادية للفساد المالي على التتمية الاقتصادية وأساليب معالجته من منظور إسلامي" ، بحث منشور في وقائع المؤتمر العلمي السابع بعنوان : مظاهر الفساد وإنعكاساتها

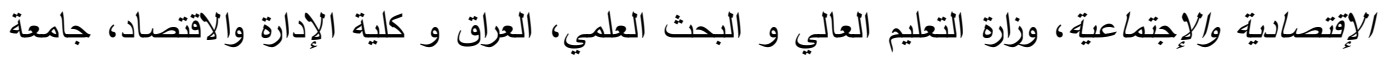

$$
\text { البصرة ، الفترة من 1-2 أكتوبر } 2015 .
$$

يونس، حنان أحد. (2016). "آليات مكافحة الفساد الإدارى والمالى"، مجلة العدل، دولة الكويت / وزارة العدل، المجلد الثامن عشر، العدد السادس والأربعين، عدد شهر إبريل، ص ص الئ 277- 284. يونس، مفيد ذنون. (2012). أتثر الفساد في النو الاقتصادي في ظل تباين مؤسسة الحكم"، مجلة تنمة الرافدين،

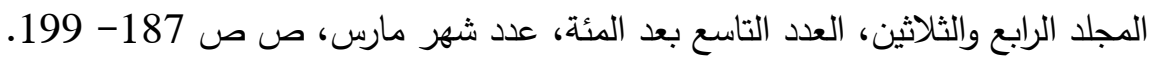

\section{References}

Abboud, Ali Sukkar. (2010). Analysis of Pictures and Causes of Financial and Administrative Corruption: An Exploratory Study of a Selected Sample in the Province of Diwaniyah, Al-Qadisiyah Journal of Administrative and Economic Sciences, 12(1), 119-138. (in Arabic) 
Abdul Majeed, Mahmoud Abdel Majid. (2018). Corruption: its Definition, Pictures and Relationship to other Criminal Activities, Cairo: Nahdet Misr Publishing House. (in Arabic)

Agon, Ahmed. (2017). Legal Rooting and Jurisprudential Analysis of the Style of Legislative Delegation in Morocco and France, Moroccan Journal of the Legal and Political Organization, 1(12), 37-176. (in Arabic)

Ahmed, Ashraf Mr. (2016). The Impact of Corruption on Economic Growth in Egypt, Journal of Commercial Research, Zagazig University, Faculty of Commerce, 39(1), 257-279. (in Arabic)

Al Khalifa, Lubna Ali. (2015). Transparency and Combating Corruption: A Case Study of Gulf Cooperation Council Countries According to the World Bank Indicators for Good Governance in the Period from 1996-2013, The Egyptian Journal of Commercial Studies, Mansoura University, Faculty of Commerce, 39(2), 143 164. (in Arabic)

Al Maamari, Abdul Malik Ahmed. (2013). Financial and Administrative Corruption, its Forms, Insults, and its Impact on Impeding Development: A Field Study on the Governmental Apparatus of the City of Taiz, Saleh Abdullah Kamel Center for Islamic Economy Journal, 17(50), 303-395. (in Arabic)

Al Qabas Kuwaiti Newspaper. (2018). Economy Page Entitled: "Corruption is Getting Worse in Kuwait" February 22, 2018, Issue 15123. (in Arabic)

Al-Ghamdi, Muhammad bin Ali. (2014). Manifestations of the Noble Prophet's Sunnah Fight Against Financial Corruption, Journal of the College of Sharia and Law in Tanta, 1(20), 741-808. (in Arabic)

Al-Hajj, Tariq. (2008). Manifestations of Administrative and Financial Corruption, Rumah Journal for Research and Studies, Research and Development Center for Human Resources - Ramah, 1, (4), 80-92. (in Arabic)

Ali, Mujasha Muhammad. (2016). Television and Corruption: The Role of Television and Combating Corruption, Cairo: Dar Al-Arabiya for Publishing and Distribution. (in Arabic)

Alimat, Khaled Clinic. (2020). Corruption and its Implications for Economic Development: A Case Study of Jordan, Amman: Gulf House for Publishing and Distribution. (in Arabic)

Al-Jazouli, Ahmed's friend. (2015). Fighting Corruption: An Authentic Vision, Journal of Islamic Studies, Al-Madinah International University, 1(1), 1-16. (in Arabic)

Al-Khatib, Khaled Ragheb. (2008). Administrative and Financial Corruption: Dilemma and Treatment, Experiences of Some Countries, Rumah Journal for Research and Studies, 1(4), 111-144. (in Arabic)

Al-Kubaisi, Amer Mohammed. (2000). Administrative Corruption is a Systematic Vision for Diagnosis, Analysis and Treatment, Arab Journal of Administration, 1(10), 85-122. (in Arabic)

Al-Mahrouq, Adel Ibrahim Abdullah. (2016). The Role of Islamic Sharia in Reforming Financial Corruption, Iqtisadiah Journal, Al-Mirqab University - College of Economics and Commerce, 1(4), 163-192. (in Arabic)

Al-Mulla, Moaz Suleiman. (2020). Fighting Corruption and its Relation to Sustainable Development: A Descriptive Study in Light of the Provisions of Law No. 2 of 2016 Concerning the Establishment of the Public Authority, Journal of Gulf and Arabian Peninsula Studies, Kuwait University, Academic Publishing Council, 46(77), 453-501. (in Arabic)

Al-Qurtubi, Muhammad bin Ahmed. (2005). Al-Jami 'for the provisions of the Qur'an, Cairo: Dar al-Hadith for publication and distribution. (in Arabic) 
Al-Rifai, Salama Bin Sulayem. (2015). The National Anti-Corruption Commission and its Role in Fighting Corruption: A Comparative Study, Riyadh: Law and Economics Library. (in Arabic)

Al-Tamimi, Ahmed Hamid and Al-Salami, Ibrahim. (2018). The Provisions of Personal Status Laws Between Islamic Law and the Law: A Comparative Study, Amman: Dar Al-Mu'taz for Publication And Distribution. (in Arabic)

Al-Zubaidi, Khaled Lafta Shaker. (2015). The Role of the Judiciary in Combating Corruption: An Analytical Study in the Light of Iraqi Law, Journal of Sharia and Law, United Arab Emirates University, College of Law, 21(62), 357-423. (in Arabic)

Bilbal, Hasnawi. (2019). Administrative and Financial Causes of Corruption and the Strategy to Combat It, Journal of Management and Economics Research, 1(2), 2840. (in Arabic)

Boufasa, Suleiman. (2014). The Effects of Financial and Administrative Corruption and Ways to Combat It: The Case of Algeria, Journal of Contemporary Egypt, the Egyptian Society for Political Economy, Statistics and Legislation, 105(513), 391420. (in Arabic)

Daghmash Muhammad Samer. (2018). Strategies to Combat Financial and Administrative Corruption, Criminal Confrontation And The Implications Of Financial Corruption: A Comparative Study, Amman: Center for Arab Studies for Publishing and Distribution. (in Arabic)

Dudin, Ahmed Youssef and Al-Dulaimi, Hamad Fawaz. (2011). International and Global Financial Crises, Amman: Dar Jales Al Zaman. (in Arabic)

Farhan, Khaled Ahmed. (2012). The Two Phenomena of Money Laundering and Financial Corruption and their Impact on the Iraqi Economy: A Case Study After the American Occupation of Iraq on 4/9/2003, Al-Mansour Magazine, Baghdad, 1(17), 59-87. (in Arabic)

Generosity, Hassan. (2017). Financial Corruption: Its Causes and Cure, Sawt Al-Ummah Magazine, Al-Salafi University - House of Authorship and Translation, 49(9), 5559. (in Arabic)

Grace, Manaf Merza. (2015). The Economic Effects of Financial Corruption on Economic Development and Methods of Treating it from an Islamic Perspective, a research published in the Proceedings of the Seventh Scientific Conference entitled: Manifestations of Corruption and their Economic and Social Implications, Ministry of Higher Education and Scientific Research, Iraq and the College of Management and Economics, University of Basra, period 1- October 2, 2015. (in Arabic)

Hanna, Youssef, Saber. (2016). Why are Corrupt People Increasing: A Reading in Transparency International Index, Al-Siyasa Al-Dawlia, Fifty-second year, supplement, April issue, 25-30. (in Arabic)

Ibrahim, Ibrahim Abdul Rahman. (2015). The Role of Legislation in Fighting Corruption: Sudan as a Model, Journal of Human Sciences, Al-Zaeem Al-Azhari University, 1(3), 108-134. (in Arabic)

Idris, Abdel Fattah Mahmoud. (2013). Combating the Defect of Administrative Corruption In Contemporary Societies: A Comparative Study Between Positive Law And Islamic Law, Journal of Research and Sharia Studies, 23(16), 113-150. (in Arabic)

Ismail, Ali Syed. (2019). Contemporary Research in Islamic Economics, Financial and Banking Transactions: The Economic Thought of Al-Jahiz, Alexandria: University Education House. (in Arabic) 
Ismail, Muhammad Sadiq. (2014). Administrative Corruption in the Arab World: Its Concept and Its Different Dimensions, Cairo: The Arab Group for Training and Publishing. (in Arabic)

Jarallah, Ali Muhammad. (2019). Enough Corruption, Kuwait: Sama House for Publishing and Distribution. (in Arabic)

Juma, Safaa Fattouh. (2014). The Responsibility of the Public Employee in the Framework of the Application of the Electronic Management System, Mansoura Egypt: Dar Al-Fikr and Al-Law. (in Arabic)

Kuwaiti newspaper, Al-Anbaa. (2020). Kuwait News Page Entitled: "Kuwait is the last in the Gulf and the Ninth in the Arab World in the Corruption Perceptions Index for the year 2019," 24 January 2020, issue 15760. (in Arabic)

Maatouk, Samia Mohamed. (2019). Corruption in the Arab Countries: Between Reality Difficulties and the Inevitability of Treatment, Journal of Economic Studies, Abdul Hamid Mehri University - Constantine, 6(1), 247-270. (in Arabic)

Hoda Mohamed Al sayed. (2018). The Role of Egyptian Law in Combating Financial Corruption in the State's Administrative System, Journal of Legal and Economic Sciences, Ain Shams University, Faculty of Law, 60(1), 481-544. (in Arabic)

Rababaa, Adnan Youssef. (2015). Combating the Prophet's Sunnah against Financial Corruption and its Economic Effects, Journal of Scientific Research and Islamic Studies, Ben Youssef bin Khudda University - Algeria, College of Islamic Sciences, 1(10), 66- 94.

Radi, Mazen Leilo and Al-Taie, Hamza Hassan. (2015). Administrative Corruption in the Public Service, Amman: Academic Book Center for Publishing and Distribution. (in Arabic)

Sabri, Abdul Rahman. (2006). Economics of Corruption and its Alphabet, Shu'un Arabia Magazine, League of Arab States - General Secretariat, Issue 128, January issue, 167-177. (in Arabic)

Sailor, Muhammad. (2016). The Legal Framework for Fighting Corruption: A Reading in the United Nations Convention against Corruption and a Review of the Moroccan Experience, Moroccan Journal of Local Administration and Development, 1(127), 271-304. (in Arabic)

Salem, Hanan Mohamed. (2003). The Culture of Corruption in Egypt, a Comparative Study of Developing Countries, Cairo: Dar Misr El-Mahrousa. (in Arabic)

Shamri, Hashem Muhammad. (2011). Financial and Administrative Corruption and its Economic And Social Implications, Beirut: Al-Yazouri House for Publishing and Distribution. (in Arabic)

Shamri, Hashem. (2011). Administrative and Financial Corruption and its Economic and Social Impact, Amman: Al-Yazouri Scientific Publishing House. (in Arabic)

Sharif, Mohammed bin Abdullah. (2016). Integrity in the Face of Corruption: The Experience of the Kingdom of Saudi Arabia, Riyadh: Al-Obeikan Publishing and Distribution House. (in Arabic)

Shashati, Rashid Ibrahim. (2014). The Theory of Justified Punishment and its Application in Jordanian Legislation and the Judiciary: A Comparative Study, Studies of Sharia and Law Sciences, The University of Jordan, 41(January issue), 1105-1117. (in Arabic) https://doi.org/10.12816/0026131

Shdeifat, Riad Khalif. (2020). Toward a Rashid Media Discourse with an Islamic Vision with Insight: An Analytical Study of Contemporary Media Discourse, Amman: Dar Al-Jinan for Publishing and Distribution. (in Arabic) 
Shehata, Hussein Hussein. (2011). Financial Corruption: Its Causes, Its Forms and Its Remedy, Islamic Awareness Magazine, State of Kuwait, Ministry of Awqaf and Islamic Affairs, 48(552), 26-27. (in Arabic)

Talib, Alaa Farhan. (2010). Strategies to Combat Administrative and Financial Corruption: A Comprehensive Vision, Research Published in the Annual General Conference Entitled: Towards A National Strategy To Combat Corruption, Arab Administrative Development Organization - Egypt, the period from July 1-2, 2010. (in Arabic)

Suhaila, Abdul Zahra. (2015). Administrative and Financial Corruption in Iraq: Manifestations, Causes and Treatments, Journal of Management and Economics, Al-Mustansiriya University, College of Administration and Economics, 38(102), 49-61. (in Arabic)

Moharib, Abdul Aziz Qasim. (2016). Administrative Corruption, Journal of Finance and Trade, Trade Club, (507), 6-33. (in Arabic)

Younes, Moufid Thanon. (2012). The Impact of Corruption on the Economic Nation in Light of the Difficulty in the Institution of Governance, Tanmat Al-Rafidain Magazine, 34(109), 187-199. (in Arabic)

Yunus, Hanan Ahmed. (2016). Mechanisms for Combating Administrative and Financial Corruption, Justice Magazine, State of Kuwait / Ministry of Justice, 18(46), 277-284. (in Arabic) 